\title{
Working
}

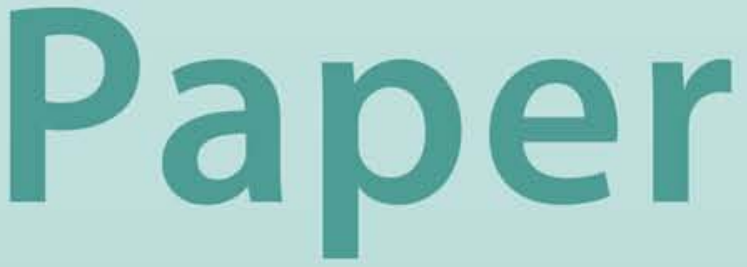




\section{The New Economy and Global Stock Returns}

Robin Brooks and Luis Catão 


\title{
IMF Working Paper
}

\author{
Research Department \\ The New Economy and Global Stock Returns
}

\author{
Prepared by Robin Brooks and Luis Catão ${ }^{1}$ \\ Authorized for distribution by Tamim Bayoumi
}

December 2000

\begin{abstract}
The views expressed in this Working Paper are those of the author(s) and do not necessarily represent those of the IMF or IMF policy. Working Papers describe research in progress by the author(s) and are published to elicit comments and to further debate.
\end{abstract}

This paper revisits the relative importance of global versus country-specific factors underlying stock returns. It constructs a new firm level data set covering emerging and developed markets and estimates a simple factor model, which breaks down stock returns into a global business cycle factor, global industry factors, country-specific factors and firmlevel effects. The results indicate that the share of variation in stock returns explained by global industry factors has grown sharply since the mid-1990s, at the expense of countryspecific factors. Foremost among the global factors is a "new economy" factor, which has become a key determinant of global stock returns.

JEL Classification Numbers: F36, G11, G15

Keywords: stock markets, portfolio diversification, international financial integration, new economy.

Authors' E-Mail Addresses: rbrooks2@imf.org, lcatao@imf.org

${ }^{1}$ Special thanks go to Tam Bayoumi and Manmohan Kumar for extensive comments on an earlier draft, to Ben Sutton for outstanding data work, and to Janice Hospod of Datastream for answering our many queries. We are also grateful to Fabio Canova, Paolo Mauro, Papa Ndiaye, Eswar Prasad, Anthony Richards, and Nikola Spatafora for many helpful comments and suggestions, and Lisa Nugent and Marlene George for assistance with the preparation of this paper. 


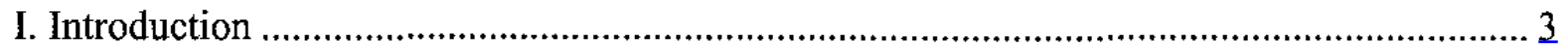

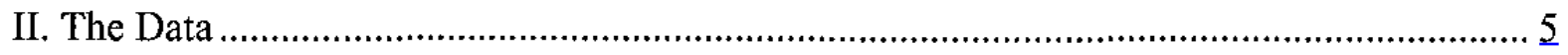

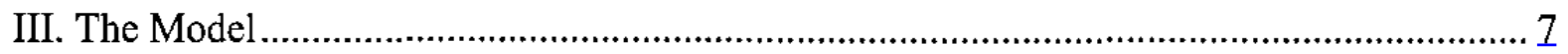

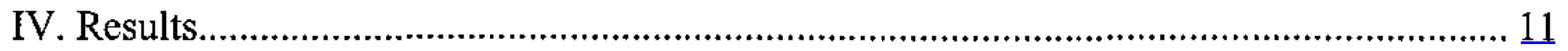

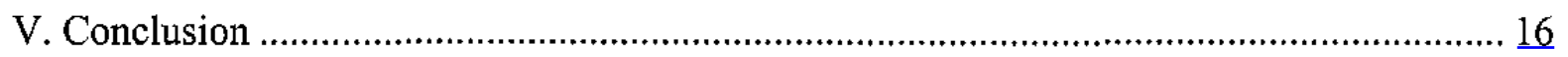

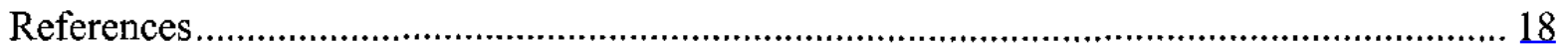

Tables

1A.Data on Number of Firms by Country and Industry, December 1999................................

1B.Data on Market Capitalization in Billions of US Dollars by Country

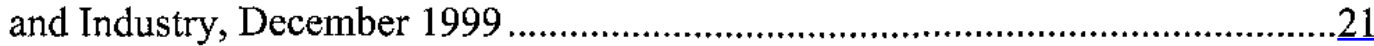

1C.Data on Market Capitalization in Percentage of the Sample Total by Country

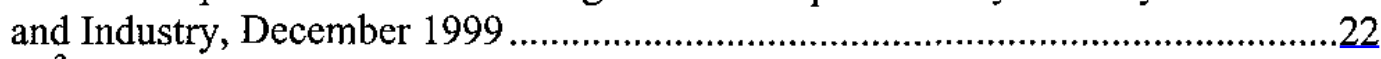

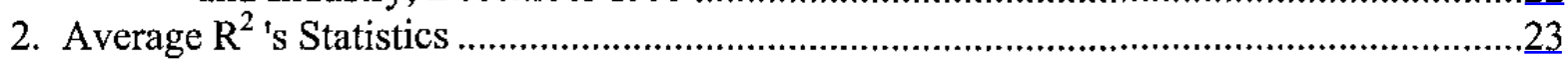

3. Value-Weighted \$ Returns Model: FTSE Industry Effects-Industralized Countries........24

4. Value-Weighted Percentage Returns Model: FTSE Industry Effects.................................25

5. Standard Deviations of Country Index Returns, Pure Country Effects and Composite Industry Effects: Based on Value-Weighted Percentage

Regressions Without Size Effects

6. Pure Country Effects and Composite Industry Effects in Percentage

Country Portfolio Return Standard Deviation (Based on Value-Weighted

Percentage Regressions without Size Effects (Table 6)) ……..............................28

7. Value-Weighted Dollar Returns Model: FTSE Industry and Size Effects ............................29

Figures

1. The Global Factor and Industry Effects on Stock Returns ...............................................31

2. The Global Factor and Country Effects on Stock Returns .................................................32

3. The Global Factor and Asian/Latin American Country Effects on Stock Returns ...............33

4. Cummulative Industry Effects on Global Stock Returns....................................................34

5. The Global Factor and Firm Size Effects on Stock Returns................................................35

6. Standard Deviation of Residuals of Value Weighted Model with Size Effects ...................36

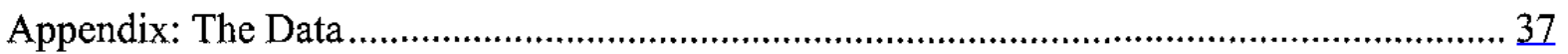




\section{INTRODUCTION}

A longstanding empirical regularity in international equity markets is the low correlation among country portfolio returns. A number of explanations have been advanced to explain this stylized fact. First, instead of diversifying across markets and holding a portfolio that mirrors the global basket of securities, investors exhibit home bias in selecting stocks. If the marginal investor in French stocks lives in France and the marginal investor in U.S. stocks lives in the U.S., with each investor pricing stocks relative to other assets in the home market, country portfolios may in part reflect the different sentiment of French and U.S. investors. Second, country portfolios differ in industrial composition. For example, relative to Switzerland the Swedish stock market contains more firms in basic industries, while the Swiss index has more banks. To the extent that basic industries and banks are imperfectly correlated, the country indices of Sweden and Switzerland will be imperfectly correlated. Third, economic shocks may affect companies differently across countries. This may be because shocks are regional in nature, such as a policy change that is specific to one country. Alternatively national markets may respond differently to global shocks because institutional differences affect the transmission of these shocks to asset values.

Prior empirical work by Beckers et. al. (1992) and Heston and Rouwenhorst (1994) has shown that differences in the industrial makeup of countries play only a minor role in explaining the low degree of co-movement across national stock markets. Instead the low correlation of country portfolio returns is found to be primarily due to country-specific shocks. In other words, shocks that affect banks in Sweden differently than banks in Switzerland are more important in explaining the low correlation of national equity markets than the fact that Sweden has fewer banks. Or perhaps it is that cross-country variation in investor sentiment drives a wedge between the returns of companies that are in the same industry but in different countries. Heston and Rouwenhorst (1995) and Rouwenhorst (1999) show that these country-specific sources of return variation are dominant even in geographically concentrated and economically integrated regions such as Western Europe. They argue that country effects are likely to be even more important for stock markets that are further apart or in emerging markets, a hypothesis confirmed by Griffin and Karolyi (1998) and Serra (2000).

At the same time, there is a growing conviction in the investment community and in the financial press that globalization and the new economy are raising the importance of global industry effects in explaining return variation, at the expense of country-specific factors. A recent article in Business Week (09/11/2000) makes this point. It reports that the correlation between the S\&P 500 and the Morgan Stanley Capital International Europe-Asiaand-Far-East (EAFE) index has increased from 25 percent in 1995 to 78 percent this year. The magazine interprets this increase in co-movement in the context of three phenomena: the wave of cross-border mergers and acquisitions, which is increasing the number of multinationals and accelerating the trend towards global industry sectors (consolidation within industries has accounted for three-quarters of all cross-border mergers over the past 
two years, against half in the early 1990s); the growing importance of high-tech companies, which are especially global in their reach (40 percent of Yahoo!'s customers are outside the U.S., while Finland's Nokia has a 37 percent share of the U.S. cellular market); and finally the fact that the internet makes it easier for investors to gather information on foreign companies, reducing the rationale for home bias in portfolio composition. Business Week concludes that, because companies are going global and national stock markets are increasingly correlated, diversifying across countries no longer offers investors the same amount of protection it once did. Perhaps as a result, the number of funds that invest globally by industry has been growing recently-14 of these funds were launched in just the past two years, with another 11 having filed registration statements to open soon. ${ }^{2}$ To quote one fund manager: "The world has changed, and the industry dimension matters more now than the country dimension."

This perception on the part of the investment community has been partly corroborated by recent research. Baca et al. (2000) provide evidence that, while country factors remain more important, "pure" industry factors have grown in importance in the 1995-99 period across seven developed countries. Using a broader sample of developed countries, Cavaglia et al. (2000) find that the importance of industry factors has not only grown sharply in recent years but in fact outweighs that of country factors during the 1997-99 period. This paper extends these studies in two ways. First, it uses a new and much broader data set that covers up to 5,507 firms in 21 developed and 19 emerging markets, and accounts for around 90 percent of stock market capitalization across sample countries according to the $2000 \mathrm{IFC}$ stock market fact book. We use this data to estimate a dummy-variable factor model of stock returns similar to that used in previous studies. Specifically, the model distinguishes between four kinds of factors: a global effect that captures broad co-movement across stock returns, in effect controlling for a global business cycle; country-specific effects that control for national determinants of stock returns; global industry-specific effects, which reflect the technological and product market characteristics of 10 broad sectors as defined by the FTSE; and global size effects, which control for risk-premia associated with smaller firms. Second, we use this model to measure the relative importance of a "new economy" factor in determining global stock returns. This allows us to examine the anecdotal evidence referred to above, that the new economy is promoting the importance of sectoral relative to country diversification in portfolio strategies.

${ }^{2}$ A recent global equity markets strategy report by ING Barings entitled "Global sectors here to stay?" notes that, although the influence of global sectors on equity market returns so far this year has dimmed from the extremes of late 1999, the "sector effect" has undoubtedly persisted. The New York Times Business Day section has recently focused on the continuing divergence between the behavior of technology stocks and that of the overall market (see, e.g., "Technology Breeds Volatility and All Major Gauges Advance" (11/1/00) or "Nasdaq, Dow and New Principles of Physics for Wall Street" (10/31/00)), while the May 2000 issue of the IMF World Economic Outlook has highlighted the growing cross-border correlation of technology stock prices despite divergences in national business cycles. 
The main results are as follows. First, the importance of global effects in explaining return variation has increased across the board since the mid-1990s. Meanwhile countryspecific effects associated with developed countries have lost some explanatory power over the same period, while those for some emerging markets have increased dramatically in the wake of the Asian financial crisis of 1997-98. While the growing explanatory power of global factors may be seen as an indication that equity markets have become more integrated, it is also possible that the greater return variation explained by global factors is simply capturing that stock markets become more tightly correlated during crisis periods. Second, the fraction of return variation explained by global industry effects is on average 28 percent across stock markets in developed countries from mid-1997 onwards, far above the 7 percent identified by Heston and Rouwenhorst (1995). Even including emerging markets, the return variation explained by global industry factors amounts to 23 percent, far in excess of the 4 percent of Griffin and Karolyi (1998). This is clear evidence that industry sectors are becoming more important in diversifying portfolio risk. Third, a global industry factor associated with information technology far outpaces all other global factors in explaining return variation, a likely indication that it is not simply capturing tighter correlations due to the Asian crisis but the disparate behavior of technology stocks relative to the market as a whole. As a result, this paper finds evidence to support the notion that the new economy is raising the profile of industry sectors in portfolio diversification strategies. More broadly, this emerging "high-tech" effect suggests that the market bifurcation between old and new economy stocks-so apparent in some national equity markets-is in fact a global phenomenon that began as early as 1995 . Fourth, the growing importance of the global information technology effect is robust across different specifications, notably for equalversus value-weighting. It is also the case that the results are qualitatively unchanged when global size effects are added to the factor model, i.e., when we try to control for the possibility that an industry in one country may be different from the same industry in another country, using firm size to do this.

In a nutshell, the key result of this paper is to identify the growing importance of the global industry factor associated with the disparate behavior of technology stocks and their remarkable co-movement across markets. However, the paper is mute on whether this phenomenon reflects changing fundamentals or a global bubble. If this trend reflects changing fundamentals, the results suggest that the new economy revolution began earlier and is more global than previously thought. If the phenomenon is a bubble, it is possible that high-tech stocks are becoming a new conduit for financial contagion at the global level.

The remainder of the paper is structured as follows. Section II describes the data. Section III explains the factor model, while Section IV discusses the estimation results. Section V concludes.

\section{THE DATA}

The data cover monthly total returns and market capitalizations for up to 5597 firms in 21 developed and 19 emerging stock markets over the period March 1986 to August 
$2000 .{ }^{3}$ Firms are grouped into one of 10 FTSE industry sectors: resources, basic industries, general industries, cyclical consumer goods, non-cyclical consumer goods, cyclical services, non-cyclical services, utilities, information technology and financials. The appendix provides a detailed breakdown of the composition of these broad industry groups. While several recent papers argue in favor of a finer industry disaggregation, the level of disaggregation used here is sufficient because it follows to the traditional industry breakdown used by portfolio managers and contrasts information technology - a key "new economy" sector - with "old economy" sectors. ${ }^{4}$

Central to this paper is that the data be a realistic and unbiased representation of the global stock market. Table 1 provides a snapshot of the sample in December 1999. In that month the total number of firms amounts to 5,507, while the total number of listed firms in the 40 sample countries was 35,044 in that month, according to the 2000 IFC stock market fact book. ${ }^{6}$ The sample covers only 16 percent of listed firms. Looking at market capitalization measured in US dollars the picture is very different however. The total capitalization of the sample comes to $\$ 30,749$ billion, almost 90 percent of stock market capitalization in the 40 sample countries as measured by the IFC. Coverage deteriorates

${ }^{3}$ Monthly total returns are computed in local currency using data from Datastream/Primark. The return calculation assumes immediate reinvestment of dividends. These local currency returns are converted to U.S. dollar returns using end-of-month spot exchange rates. The beginning-of-month stock market capitalizations are converted into U.S. dollars using the beginning-of-month $\$$ price of one unit of local currency.

${ }^{4}$ While Griffin and Karolyi (1998) note that a finer industry disaggregation may yield a more accurate measure of industry effects, their main result - the dominance of country-specific effects - hardly changes with the move to a finer industry breakdown (they have nine broad industry categories and 66 more disaggregated industries). Meanwhile, Heston and Rouwenhorst (1995) much quoted results are based on only seven broad industry categories.

${ }^{5}$ Country abbreviations are as follows: United States (US), United Kingdom (UK), France (FR), Germany (GE), Italy (IT), Japan (JA), Canada (CA), Australia (OZ), Austria (AU), Belgium (BE), Denmark (DE), Hong Kong (HK), Ireland (IR), the Netherlands (NE), New Zealand (NZ), Norway (NO), Spain (SO), Sweden (SW), Switzerland (CH), Finland (FI), Greece (GR), Portugal (PO), Luxembourg (LU), Malaysia (MA), Singapore (SI), South Africa (SA), South Korea (SK), Thailand (TH), Philippines (PH), Taiwan (TA), Argentina (AR), Mexico (ME), Turkey (TU), Chile (CL), India (IN), Indonesia (ID), Peru (PE), Colombia (CO), Poland (PL) and China (CI).

${ }^{6}$ Sector abbreviations are Resources (Res), Basic Industries (Bas), General Industries (Gen), Cyclical Consumer Goods (Cgd), Non-Cyclical Consumer Goods (Ngd), Cyclical Services (Csr), Non-Cyclical Services (Nsr), Utilities (Utl), Information Technology (It) and Financials (Fin). 
somewhat towards the beginning of the sample. In December 1990, for instance, the total number of firms amounts to 3,177 , while the total number of listed firms in the 40 sample countries was 22,535 , again according to the IFC. The sample covers only 14 percent of listed firms. Total capitalization of the sample comes to $\$ 6,224$ billion, about 67 percent of stock market capitalization in the 40 sample countries as measured by the IFC. In part, the deterioration in coverage highlights two important deficiencies of the data set. First, it is subject to survivorship bias, meaning that only firms surviving over the full sample period are covered. No doubt this bias is important, especially in the context of global shocks such as the Mexican and Asian crises. But it is most likely offset at least in part by the fact that the data omit a large number of small firms where the risk of bankruptcy is greater. A potentially more serious flaw of the data is that it includes only post-merger companies, dropping companies that go into the merger. In the case of the merger between Mercedes-Benz and Chrysler, for example, our data cover Daimler-Chrysler but not Mercedes-Benz and Chrysler individually in the period leading up to the merger. It is possible that this may bias the estimates in favor of finding more pronounced global industry effects in more recent years in the sample.

On the positive side, the sample is far more global and comprehensive than data used in earlier studies. No single country is represented by less than 31 firms (Peru) and, in the case of large economies such as the US and Japan, coverage approaches 1,000 firms towards the end of the sample. This large cross-section dimension of the data probably eliminates any significant distortion in the econometric results arising from the deficiencies mentioned above. Moreover, to the extent that much of our analysis focuses on the variance of stock returns rather than on their mean values, the main results are not particularly vulnerable to the traditional survivorship bias problem.

\section{THE MODEL}

Following Heston and Rouwenhorst (1994) the model assumes that the return on each stock depends on four components: a global market factor $(\alpha)$, global industry factors $(\beta)$, country factors $(\gamma)$ and a firm-specific disturbance $(e)$. The return on stock $i$ that belongs to industry $j$ and country $k$ is given by:

$$
R_{i t}=\alpha_{t}+\beta_{j t}+\gamma_{k t}+e_{i t}
$$

The paper estimates a time-series for the realization of the common factor, industry factors and country factors by running the following cross-sectional regression every month:

$$
R_{i}=\alpha+\sum_{j=1}^{j} \beta_{j} I_{i j}+\sum_{k=1}^{K} \gamma_{k} C_{i k}+e_{i}
$$


where $I_{i j}$ is a dummy variable that equals one if the stock belongs to industry $j$ and zero otherwise, and $C_{i k}$ is a similar dummy variable that identifies country affiliation. There are $J$ industries and $K$ countries in total. This month-by-month approach is equivalent to a panel regression that interacts the constant as well as the industry and country effects with a time dummy-allowing for changes in the relative importance of these underlying factors over time. This is analogous to a seemingly unrelated regression model, which imposes no structure on the variance-covariance matrix that implicitly links the monthly regressions.

Equation (2) cannot be estimated in its present form because it is unidentified due to perfect multicollinearity. Intuitively, this is because every company belongs to both an industry and a country, so that industry and country effects can be measured only relative to a benchmark. To resolve this indeterminacy the paper follows the literature in imposing the restriction that the weighted sum of industry and country effects equal zero at every point in time, so that the industry and country effects are estimated as deviations from the intercept $\alpha$.

$$
\begin{aligned}
& \sum_{j=1}^{J} \beta_{j} \sum_{i=1}^{N} I_{i j} x_{i}=\sum_{j=1}^{J} \beta_{j} w_{j}=0 \\
& \sum_{k=1}^{K} \gamma_{k} \sum_{i=1}^{N} I_{i k} x_{i}=\sum_{k=1}^{K} \gamma_{k} v_{k}=0
\end{aligned}
$$

where $N$ is the total number of firms in a given month. Equation (2) is estimated using weighted least squares, with each stock return weighted by its beginning-of-month share of (sample) world stock market capitalization $x_{i}$. Then $w_{j}$ corresponds to the market capitalization of industry $j$ as a share of the (sample) global market, while $v_{k}$ is the market capitalization of country $k$ as a share of the total.

The interpretation of these coefficients is straightforward. The intercept $\alpha$ reflects the return on the value-weighted portfolio of stocks across all sample countries - a benchmark against which industry- and country-specific effects are measured. Because (2) is estimated monthby-month, $\alpha$ will vary over time, capturing the impact of the global business cycle on stock returns across industries and countries. The estimated industry and country coefficients represent excess returns relative to this return. For example, $\beta_{j}$ measures the excess return on a portfolio of stocks in industry $j$, which is diversified to the same degree as the valueweighted global portfolio across countries. Similarly $\gamma_{k}$ is the excess return on a portfolio of stocks in country $k$ with the same industry composition as the value-weighted global portfolio. As long as no two countries in the sample have exactly the same proportion of firms across industries, there is no identification problem in estimating these industryneutralized country effects and country-neutralized industry effects simultaneously. ${ }^{7}$

${ }^{7}$ For the special case when $x_{i}=1$ for all $i, w_{j}$ is simply the number of firms in industry $j$, while $v_{k}$ is the number of companies in country $k$. In this setting the estimate of $\alpha$ gives the 
This model is useful in explaining differences in stock market performance across countries. The weighted sum of stock returns for country $k$ has three components: the global factor, the weighted sum of industry effects and a country effect.

$$
\hat{R}_{k}=\hat{\alpha}+\sum_{j=1}^{J} \hat{\beta}_{j} w_{j}^{k}+\hat{\gamma}_{k}
$$

Equation (5) shows that there are two reasons that country performance differs from that of the global portfolio. The first is that industrial composition differs across countries. The weights $w_{j}^{k}$ differ across countries $\left(w^{k}{ }_{j}\right.$ is the share of industry $j$ in the total market capitalization of country $k$ ), so that depending on industrial composition countries are subject to different industry effects. The second is the country effect, which accounts for differences in the return on stocks in country $k$ relative to stocks in the same industry but located in another country.

A key deficiency of this approach is that it cannot accommodate interaction terms between industry and country effects. This is important because industry effects may be country-specific, especially if markets are segmented or during crisis episodes. We go beyond Heston and Rouwenhorst (1994) in trying to address this issue, using size dummies to proxy for country-specific industry effects, where the cross-section of $\$$ capitalizations is divided into quintiles and affiliation denoted using dummy variables. As above, they weighted sum of coefficients is restricted to zero, so that the coefficients represent size riskpremia that are measured relative to the return on the (sample) world value-weighted portfolio. It is hoped that these size coefficients will control for the fact that a bank in Indonesia, say, is different from a bank in Germany, using its lower $\$$ capitalization as a proxy.

The literature has used the factor model represented in equation (2) in three ways to measure the relative importance of country and industry effects in determining stock returns. Given that the explanatory variables are orthogonal by construction, one approach is to compare the $\mathrm{R}^{2}$ in (2) once one of the variables is omitted with that of the full model (see, e.g., Beckers and al. 1996). The difference in the cross-section of explanatory powers then measures the contribution of the omitted variable to explaining stock returns in a given period t. Breaking the sample into distinct sub-periods and averaging those cross-section $R^{2} s$,

return on the equal-weighted portfolio of stocks in the sample, the estimate of $\beta_{j}$ gives the excess return on a portfolio of stocks in industry $j$, which matches the equal-weighted global portfolio in geographical diversification, and $/ k$ gives the excess return on a portfolio of stocks from country $k$ with the same industrial composition as the equal-weighted global portfolio. Equal-weighting in this setting should be seen as weighting each firm equallyregardless of capitalization. Countries and industries are still weighted differently depending on their representation in the data set. 
it is possible to check whether the contribution of a given factor is rising or declining over time.

A second measure of the relative importance of industry versus country effects is to compare the average absolute value of the coefficients $\hat{\beta}_{j}$ and $\hat{\gamma}_{k}$ (Heston and Rouwenhorst, 1995, Rouwenhorst, 1999). If the mean of the absolute values of $\hat{\beta}_{j}$ across industries is smaller than that of $\hat{\gamma}_{k}$ across countries over a given period, this is indicative of a lower importance of industry- relative to country-effects during that period. Also, looking at those mean estimates across countries and industries over time sheds some light on what is driving the predominance of country or industry effects. For instance, a rise in the absolute mean value $\hat{\beta}$ for a specific sector $\mathrm{k}$ (e.g. information technology) may explain the growing importance of global industry relative to country factors.

Third, the relative importance of the distinct factors can be measured by the timeseries volatility of the factor estimate. As the factor loadings in the model are either zero or unity, the explanatory power of a factor can be simply measured by the factor return variance. This permits testing several hypotheses regarding global market integration, the importance of industry versus country factors in the overall sample, as well as identifying which sector(s) or countries appear to explain the rising importance of one factor relative to another. For instance, if the global stock market is becoming more integrated over time, the variance of the global factors-the global market, industry, and size factors-should be increasing relative to the variance of the country factors. ${ }^{8}$ Using (5), we can measure, on a country by country basis, the proportion of the total variance in stock market returns $\hat{R}_{k}$ that is explained by changes in the global return $\hat{\alpha}$ versus changes in industry composition effects $\left(\sum_{j=1}^{J} \hat{\beta}_{j} w_{j}^{k}\right)$ or changes in the country factor $\hat{\gamma}_{k}$. And, again, splitting the sample and computing such variances over sub-periods allows us to test whether such global industry effects have in fact grown in importance, the extent to which this phenomenon has been more pronounced in certain countries (or group of countries), and whether such a growing importance of global factors has been mostly due to the particular behavior of information technology or any other individual sector(s).

Each of these measures provides useful information that is in some respects complementary. For instance, the cross sectional $\mathrm{R}^{2}$ statistic gives us the net percentage contribution of country, industry, and size factors to explaining stock returns at a given point

\footnotetext{
${ }^{8}$ As discussed further below, there are reasons not to expect the variance of the global factor to increase monotonically with international financial integration. In particular, the variance of global factors should be expected to accelerate during financial panics (as investors tend to move away from equity markets altogether) and decline during "tranquil" periods.
} 
in time, since industry, country and size dummies are orthogonal in every cross-section. However, the same statistic does not allows us to measure how much of the time series variations in returns is explained by changes in the global factor $\hat{\alpha}$ (as the latter is fixed every cross-section), and is therefore insufficient to gauge the degree of global market integration. Measuring the latter requires estimates of mean excess returns for each industry/country (i.e. the second measure discussed above) and their respective Sharpe ratios, as will be argued below. Finally, measures of volatility decomposition based on equation (5), while allowing us to measure the contribution of global and industry composition factors to overall stock returns in each country, can only provide an estimate of their gross contributions since the right-hand side variables in (5) are not orthogonal over time. ${ }^{9}$ In light of the limitations of these different measures as well as their complementarities, we shall look at all of them, rather than singling out one as some previous studies have done.

\section{Results}

As noted above, both the equal- and value-weighted regressions use monthly total returns expressed in U.S. dollars. ${ }^{10}$ The value-weighted regressions weight returns by beginning-of-month U.S. dollar capitalization as a share of the (sample) global stock market.

Table 2 reports the average $\mathrm{R}^{2}$ for equal- and value-weighted models for different combinations of explanatory variables. Those $\mathrm{R}^{2} \mathrm{~s}$ are cummulative, i.e., the first row in each sub-section of the table presents the $\mathrm{R}^{2}$ for equation (2) setting the dummy I to zero, whereas the two subsequent rows report the $\mathrm{R}^{2}$ of the models including $\mathrm{I}$ and $\mathrm{C}$, and then including $\mathrm{I}$, $\mathrm{C}$ and the size dummy. Thus, the net contribution of the additional factor (industry or size) to the cross-section of stock returns will be given by the difference between the $\mathrm{R}^{2}$ reported in two successive rows. In presenting these results we breakdown the sample into two - one covering developed countries only and the other including emerging markets as well. The rationale for focusing only on developed economies in the first set of regressions is twofold. One is data heterogeneity. Data for several emerging markets only becomes available in the 1990 s, whereas data for mature economies spans the entire sample period. The other reason is that most previous studies on the relative importance of country versus industry effects

\footnotetext{
${ }^{9}$ That is, the time series covariances of country and industry factors are not necessarily zero, though there are reasons to expect such covariances to be relatively small, as indeed our estimates indicate (see below)

${ }^{10}$ The basic results do not change, however, when local currency returns are used. This is because exchange rate variations are relatively small compared with the variation in local currency returns. Since the analysis is done in $\$$ terms, it reflects the perspective of an unhedged equity investor whose objective is to maximize $\$$ returns.
} 
have focused on mature markets. Thus our results for mature markets allow a more direct comparison with the preceeding literature.

For the equal weighted model, the results of the $\mathrm{R}^{2}$ statistic are very similar to those of Becker et al. (1996) in that industry factors account for only 3 to 4 percent of the cross sectional variation of stock returns in developed countries. However, the same equal weighted model points to a declining importance of country factors in explaining stock returns throughout the 1990 s (both among developed countries and for the whole sample), while the importance of the industry-affiliation factor rises (albeit marginally) during the 1990 s.

A better fit but different estimates of the contribution of each factor are obtained on the basis of value-weighted regressions. Intuitively, these differences are in fact to be expected since the equal-weighted model exaggerates the importance of emerging markets and of lower capitalization firms in the composition of the global portfolio. To the extent that the dispersion of returns in those countries and firms tend to be more heterogenous crosssectionally, the role of both the global market factor $\alpha$ and global industry factor $\beta$ tend to be downplayed. Accordingly, table 2 shows that industry factors explain a much higher proportion of the cross-sectional dispersion of stock return variations in the value-weighted model, both for the whole sample as well as among industrial countries. Moreover, the valueweighted model points to a more significant rise in the net explanatory power of industry effects over the 1990s. A counterpart of it is the decline in country effects which, again, is steeper than in the equal-weighted regressions, though also in the same direction. As will be seen below, this steep decline in country effects is consistent with the findings of the variance decomposition analysis based on equation (5) which points to the greater role of the global market factor $\hat{\alpha}$ and of the industry-specific coefficients $\beta$ 's in explaining the total timeseries variance of stock returns in recent years. In all regressions and sub-periods, size effects turned out to be far less important than country- or industry-affiliation effects.

Tables 3 and 4 present period averages of the cross-section mean estimates and the time-series variance of those mean estimates by industry and country. Table 3 covers developed countries only while table 4 reports results for the whole sample including emerging markets. ${ }^{11}$ Each table gives the means for the global, country, and industry factors over the relevant period, the standard deviations of each of these factors over time, and the corresponding Sharpe ratios. As explained above, while the means of the industry and country factors represent excess returns or risk-premia relative to the global (sample) portfolio, the importance of each factor is given not only by the absolute value of its mean, but also by the standard deviation of this excess return over time, as the latter reveals how much variation in stock returns is explained by a particular factor.

11 The results of the equal-weighted regressions are not reported to save space, as they are broadly similar to the results of the value-weighted regression. They are available from the authors upon request. 
In this context, tables 3 and 4 provide us with three sets of measures of global market integration. The first measure is based on the standard deviations of the global factor $\alpha$ and country-specific factors; as markets become more integrated, the standard deviation of the former should rise relative to that of the latter. Second, greater market integration worldwide would tend to have a counterpart in the higher variance of global industry effects relative to country effects, implying that the fact that a firm belongs to a certain industry becomes more important in explaining the variation of its return over time than the fact that it belongs to a certain country. A third measure is the Shape ratio. As equity markets become more fully integrated, the risk-adjusted excess returns on different countries relative to the (sample) global portfolio should converge, i.e., the dispersion of Sharpe ratios across countries should decline. $^{12}$

The main results are as follows. First, the importance of global effects in explaining return variation (measured by their time-series variability) has increased across the board since the mid-1990s. This is apparent from Figure 1, which plots rolling 3-year standard deviations of the industry excess returns over the sample period. ${ }^{13}$ Meanwhile countryspecific effects associated with developed countries have lost some explanatory power over the same period (Figure 2), which is also reflected in the decline of the dispersion of Sharpe ratios across countries between 1986/88 and 1997/2000. Regarding emerging markets, however, the role of country factors in Asia has increased dramatically in the wake of the 1997 financial crisis, while those for Latin America continue to trend down (Figure 3). Over the sample period as a whole, the standard deviations of the global portfolio return and the global industry factors describe a U-shape, suggesting that they are at least in part picking up greater co-movement across national equity markets in crisis periods. The sample period begins after all just before the 1987 stock market crash and the 1991 Gulf War and ends three years after the Asian crisis.

However, the global industry factor associated with information technology far outpaces all other global factors in explaining return variation, a likely indication that it is not

\footnotetext{
${ }^{12}$ While previous studies have not considered this measure of market integration, it seems important to do so because stock markets tend to move more closely together during more volatile crisis periods-hardly a sign that they are becoming more integrated. As these periods are usually associated with higher dispersion of the mean as well as of the variance of stock returns across countries, one ideally wants a measure that captures both effects. The Sharpe ratio is usually defined as the average equity return minus that of the risk-free asset (i.e. the excess return on the equity) divided by the standard deviation of the equity return. This paper parallels this definition, but adapts it to the setting of the factor model. The Sharpe ratio used here divides the (time-series) average excess industry or country return relative to the global portfolio return, which is time varying, by the standard deviation of this excess return. This measure corresponds to a risk-adjusted excess return.

${ }^{13}$ Figures 1 through 3 are based on the value-weighted model with size effects.
} 
simply capturing tighter correlations due to the Asian crisis but the disparate behavior of technology stocks relative to the market as a whole. ${ }^{14}$ This can be clearly seen in Figure 1. More broadly, the emerging "high-tech" effect suggests that the market bifurcation between old and new economy stocks--so apparent in some national equity markets-is in fact a global phenomenon that began as early as 1995 . Figure 4 underscores this point by showing the disparate behavior of the country-neutralized pure industry returns on information technology versus "old economy" industries. By tilting their portfolios towards information technology stocks, investors could have earned significant excess returns relative to the global market from 1995 onwards. This point is underlined by the fact that the Sharpe ratio on information technology stocks has been much greater than for other industries. ${ }^{15}$

Turning to the enlarged sample of countries (Table 4), these key results continue to hold. Global factors tend to describe a U-shape pattern over the full sample period, while the information technology factor grows disproportionately in importance. However the countryspecific effects of some emerging markets are extremely important. Over the entire sample period the average absolute country effect for the value-weighted regressions clearly outweighs the global factor and the industry factors. Moreover, though country factors trend down on average from the late $1980 \mathrm{~s}$ through 1997, they rise sharply in the period 1997 to 2000 for some emerging markets. This result, coupled with the rise in the standard deviation of the global factors during the same period, may be reflecting not only an ongoing trend toward market integration but also the greater dispersion of country stock market performances in the wake of the financial crises of the late 1990s. This interpretation is buttressed by the sharp rise in the standard deviations of the respective country factors for Asian economies since mid-1997, at the same time as we observe a decline in the country factor variances for emerging market economies which performed relatively well through the Asian financial turmoil (e.g. Mexico).

${ }^{14}$ The global information technology factor is especially pronounced in the equal-weighted regressions. This is because the sample as a whole has a maximum of 624 information technology stocks worldwide, with the U.S. accounting for 277 or 44 percent of these. In capitalization terms however the picture is very different. Information technology stocks amount to about 24 percent of global market capitalization, with U.S. information technology companies accounting for about 17 percent of the world market. In capitalization terms the U.S. therefore accounts for 71 percent of all information technology companies. As a result the value-weighted regressions attribute more of the excess returns on U.S. information technology companies to the U.S. country factor, rather than to the information technology industry factor.

${ }^{15}$ It is worth noting that the industry effects associated with the non-cyclical services sector, which includes telecommunication firms, and the cyclical services sector, which includes media companies, do not experience significant gains in their ability to explain return variation. Perhaps this is an indication that information technology is the key "new economy" sector. 
Table 5 gives the standard deviations of the country index returns $R_{j}$ (calculated from the raw data), along with the standard deviations for the "pure" country effects and the composite industry effects, computed from equation (5). Table 6 presents the same results in terms of percentage contributions, i.e., dividing the "pure" country and composite industry effects by the total country index return. ${ }^{16}$ It shows that for the entire sample period composite industry effects explain about 19 percent of country return variation in developed countries, a number that rises to 28 percent from mid-1997. For the full cross-section of countries, these numbers are slightly lower, but still compare favorably to earlier results in the literature.

As a further test of robustness we consider whether firm-size effects can explain return variation - a fact that has been highlighted in the asset pricing literature generally and further explored by recent research showing that the dispersion of small cap returns tends to increase during business cycle downswings relative to upswings (Perez-Quiros and Timmerman, 2000). Moreover, as noted above, there may be interaction effects that are not captured in the factor model because banks in Indonesia may be very different from banks in Germany. This paper uses size dummies to proxy for country-specific industry effects, where the cross-section of $\$$ capitalizations is divided into quintiles and affiliation denoted using dummy variables. The weighted sum of these size coefficients is restricted to zero, so that the coefficients represent risk-premia measured relative to the return on the (sample) world value-weighted portfolio. Theory would suggest that smaller firms should have a positive risk-premium over the market return, to compensate for higher bankruptcy risk, in effect equating the risk-adjusted return to that of larger, less risky firms.

Rather counterintuitively, the results in Table 7 shows that firms in the lowest quintile of market capitalizations (the $1^{\text {st }}$ quintile) actually earn a negative risk-premium relative to the market, a marked contrast to other papers in empirical finance. This may be the result of positive serial correlation in returns, perhaps an indication of momentum trading. It could also reflect the fact that companies with smaller capitalizations are more heavily represented in emerging markets, which were hit harder in recent crises. Certainly this is what Figure 5 suggests. The 3-year rolling standard deviation of excess returns on companies in the smallest quintile of the sample distribution picks up sharply after the Asian crisis. In any event, the key result of the paper, that the new economy is indeed raising the profile of industry sectors in portfolio diversification strategies, is robust to this modification of the model. The most likely reason why the lowest quintile has a negative risk premium relative to the existing literature is that the bottom quintile represents mostly medium rather than small cap firms because of the size bias in the sample.

${ }^{16}$ As noted above, the country and industry columns need not add up to one within each period. This is because the covariance between the two effects, while zero cross-sectionally by construction, may be different from zero over time. However, in most cases the sum of the two is very close to $100 \%$, indicating that those time-series covariances are relatively small. 
One final comment on the results. Figure 6 plots the dispersion over time of the standard deviation of residual from the cross-sectional regressions for the value-weighted specification with size effects, which covers both developed and emerging markets. This measure shows that the dispersion of the cross-sectional residual (idiosyncratic risk) increases dramatically in the run-up to significant market corrections, such as late 1987 and early 2000 . At the same time, the series displays a strong and statistically significant positive first-order serial correlation, indicative of the kind of momentum in the dispersion of asset returns pointed out in previous studies (Lo and MacKinlay, 1988; Richards, 1999). ${ }^{17}$ However, it is important to note that consistency of the estimates is unaffected by heteroscedasticity or serial correlation of the residuals. Because the industry and country effects are estimated cross-sectionally at every point in time, they are consistent as the crosssection dimension of our data goes to infinity and not subject to the heteroscedasticity bias discussed in Forbes and Rigobon (2000).

\section{Conclusion}

This paper explores whether globalization and the new economy are changing the importance of industry factors in explaining return variation, at the expense of countryspecific effects. It constructs a new data set that covers up to 5,507 firms in 21 developed and 19 emerging markets. This data set is far more global and comprehensive than data used in earlier studies, covering around 90 percent of stock market capitalization across sample countries, according to the 2000 IFC stock market fact book. It uses this data to estimate a dummy-variable factor model, which attributes returm variation to global, country-specific and firm-level factors. In particular, the model distinguishes between three kinds of global factors: a global effect that captures broad co-movement across stock returns, in effect controlling for a global business cycle; global industry-specific effects, which reflect technological and product market characteristics of 10 broad sectors as defined by the FTSE; and global size effects, which control for risk-premia associated with smaller firms.

The key results are as follows. First, the importance of global effects in explaining return variation has increased across the board since the mid-1990s. Meanwhile countryspecific effects associated with developed countries have lost some explanatory power over the same period, while those for some emerging markets have increased dramatically in the

${ }^{17}$ The estimated coefficient on the first-order autoregressive term in the time-series regression of the standard deviation of cross-sectional firms' returns on a constant and the global factor is 0.7, with a t-ratio of 13.8, for the period April 1986 through August 2000. It is also worth noting that the coefficient on the global factor in the same regression is positive and statistically significant at 1 percent, suggesting that idiosyncratic risk tends to increase during periods of higher global returns. This is consistent with the findings of Richards (1999) for a variety of asset classes, as well as those of Campbell et al. (2000) on the positive correlation between market, industry and idiosyncratic risk in US stocks. 
wake of the financial crises of the late 1990s. While it may be tempting to interpret this finding as an indication that equity markets have become more integrated in recent years, it is also possible that the greater return variation explained by global factors is simply capturing that stock markets become more tightly correlated during crisis periods. Second, the fraction of return variation explained by global industry effects is on average 28 percent across stock markets in developed countries from mid-1997 onwards, far above the 7 percent identified by Heston and Rouwenhorst (1995). Even including emerging markets, the return variation explained by global industry factors amounts to 23 percent, far in excess of the 4 percent of Griffin and Karolyi (1998). This is clear evidence that industry sectors are becoming more important in diversifying portfolio risk. Third, a global industry factor associated with information technology far outpaces all other global factors in explaining return variation, a likely indication that it is not simply capturing tighter correlations due to the Asian crisis but the disparate behavior of technology stocks relative to the market as a whole. As a result, this paper finds evidence to support the notion that the new economy is raising the profile of industry sectors in portfolio diversification strategies. More broadly, this emerging "hightech" effect suggests that the market bifurcation between old and new economy stocks-so apparent in some national equity markets--is in fact a global phenomenon that began as early as 1995. Fourth, the growing importance of the global information technology effect is robust across different specifications, notably for equal- versus value-weighting. It is also the case that the results are qualitatively unchanged when global size effects are added to the factor model. These effects are intended to proxy for the possibility that across developed and emerging markets companies may nominally belong to the same industry but actually be quite different due to differences in their relative sizes. They thus control for the possibility that an industry in one country may be different from the same industry in another country, using firm size to do this. Interestingly however, smaller firms in the sample are associated with negative risk premia relative to the global market, a marked contrast with other papers in empirical finance. This may be due to the fact that firms with smaller capitalizations being more heavily represented in emerging markets, and also reflect small caps being underrepresented in the sample.

The key result of this paper is to identify the growing importance of the global industry factor associated with the disparate behavior of technology stocks and their remarkable co-movement across markets. The simple factor model used here shows that resulting bifurcation between "new" and "old" economy stocks has in fact been a global phenomenon, rather than being limited to the United States and a handful of developed countries. However, the paper is mute on whether this phenomenon reflects changing fundamentals or a bubble. If this trend reflects changing fundamentals, the results suggest that the new economy revolution began earlier and is more global than previously thought. If the phenomenon is a bubble, it is possible that high-tech stocks are becoming a new conduit for financial contagion at the global level, with important implications for both private portfolio allocation decisions and macroeconomic policy management. 


\section{References}

Baca, S.P., B. Garbe, and R.A. Weiss, 2000, "The Rise of Sector Effects in Major Equity Markets," Financial Analysts Journal, September/October, pp. 35-40.

Beckers, S., G Connor, and R. Curds, 1996, "National versus Global Influences on Equity Returns.” Financial Analysts Journal, March/April, pp. 31-39.

Beckers, S., R. Grinold, A. Rudd, and D. Stefek, 1992, "The Relative Importance of Common Factors Across the European Equity Markets," Journal of Banking and Finance, Vol. 16, pp. 75-95.

Boyer, B. H., M. Gibson, and M. Loretan, 1999, "Pitfalls in Tests for Changes in Correlations", International Finance Discussion Paper 597, Federal Reserve Board, Washington, D.C.

Braham, L., 2000 "Conquering a Slice of the World: Funds are Dividing the Globe by Industry, Not Country," Business Week, September 11.

Campbell, J., M. Lettau, B. Malkiel, and Y. Xu, 2000, "Have Individual Stocks Become More Volatile? An Empirical Exploration of Idiosyncratic Risk," NBER working paper 7590, National Bureau of Economic Research, Cambridge.

Cavaglia, S., C. Brightman, and M. Aked, 2000, "The Increasing Importance of Industry Factors", Financial Analysts Journal, September/October, pp. 41-54.

Farrell, C., 2000, "The New Global Investor: New Rules and New Tools for a Global Strategy," Business Week, September 11.

Forbes, K. and R. Rigobon, 2000, "No Contagion, Only Interdependence: Measuring Stock Market Comovement," Unpublished Manuscript, August.

Grinold, J. and G. Karolyi, 1998, "Another look at the role of industrial structure of markets for international diversification strategies," Journal of Financial Economics 50, pp. $351-373$

Heston, S. L. and K.G Rouwenhorst, 1994, "Does Industrial Structure Explain the Benefits of International Diversification," Journal of Financial Economics 36, pp. 3-27.

Heston, S. L. and K.G. Rouwenhorst, 1995, "Industry and Country Effects in International Stock Returns," The Journal of Portfolio Management, Spring, pp. 53-58.

ING Barings Investment Strategy, 2000, "Global Equity Markets Strategy," July, 
Lo, A.K. and C. MadKinlay, 1988, "Stock Prices do not Follow Random Walks: Evidence from a Simple Specification Test," Review of Financial Studies 1, pp.41-66.

Perez-Quiros, G. and A. Timmerman, 2000, "Firm Size and Cyclical Variations in Stock Returns," The Journal of Finance, Forthcoming.

Richards, A. 1999, "Idiosyncratic Risk: An Empirical Analysis, with Implications for the Risks of Relative-Value Trading Strategies," IMF Working Paper WP/99/148, International Monetary Fund, Washington, D.C.

Roll, R., 1992, "Industrial Structure and the Comparative Behavior of International Stock Market Indices," The Journal of Finance XLVII, pp. 3-42.

Rouwenhorst, K.G., 1999, "European Equity Markets and EMU: Are the Differences Between Countries Slowly Disappearing?", Financial Analysts Journal, May-June, pp. 57-64.

Serra, A. P., 2000, "Country and Industry Factors in Returns: Evidence from Emerging Markets' Stocks," Emerging Markets Review, Vol.1, no.2. 
Table 1A. Data on Number of Firms by Country and Industry, December 1999

\begin{tabular}{|c|c|c|c|c|c|c|c|c|c|c|c|c|}
\hline & Res & Bas & Gen & Cgd & Ngd & Csr & Nsr & Utl & It & Fin & Tot & IFC \\
\hline United States & 39 & 35 & 72 & 22 & 115 & 138 & 57 & 55 & 266 & 128 & 927 & 7561 \\
\hline United Kingdom & 10 & 44 & 38 & 7 & 41 & 141 & 20 & 17 & 55 & 146 & 519 & 1945 \\
\hline France & 8 & 21 & 27 & 18 & 25 & 51 & 8 & 0 & 17 & 20 & 195 & 968 \\
\hline Germany & 2 & 20 & 36 & 30 & 19 & 24 & 8 & 8 & 17 & 31 & 195 & 933 \\
\hline Italy & 3 & 14 & 18 & 20 & 8 & 21 & 8 & 6 & 2 & 54 & 154 & 241 \\
\hline Japan & 11 & 138 & 176 & 82 & 113 & 184 & 28 & 14 & 65 & 170 & 981 & 2470 \\
\hline Canada & 40 & 29 & 22 & 3 & 16 & 49 & 13 & 15 & 15 & 33 & 235 & 3767 \\
\hline Australia & 20 & 10 & 10 & 2 & 15 & 28 & 8 & 3 & 9 & 45 & 150 & 1217 \\
\hline Austria & 1 & 9 & 7 & 2 & 4 & 3 & 2 & 2 & 2 & 16 & 48 & 97 \\
\hline Belgium & 0 & 10 & 11 & 2 & 8 & 9 & 6 & 3 & 6 & 31 & 86 & 172 \\
\hline Denmark & 0 & 4 & 6 & 2 & 10 & 13 & 2 & 0 & 2 & 7 & 46 & 233 \\
\hline Hong Kong SAR & 1 & 4 & 17 & 6 & 3 & 29 & 7 & 3 & 10 & 47 & 127 & 695 \\
\hline Ireland & 8 & 6 & 2 & 2 & 11 & 9 & 0 & 0 & 3 & 7 & 48 & 84 \\
\hline Netherlands & 9 & 11 & 11 & 4 & 13 & 24 & 9 & 0 & 16 & 31 & 128 & 344 \\
\hline New Zealand & 2 & 5 & 2 & 1 & 4 & 14 & 1 & 7 & 0 & 12 & 48 & 114 \\
\hline Norway & 9 & 4 & 7 & 2 & 2 & 9 & 1 & 1 & 7 & 6 & 48 & 195 \\
\hline Spain & 2 & 27 & 11 & 4 & 15 & 19 & 6 & 7 & 1 & 28 & 120 & 718 \\
\hline Sweden & 0 & 8 & 18 & 1 & 2 & 5 & 3 & 2 & 14 & 12 & 65 & 277 \\
\hline Switzerland & 0 & 19 & 41 & 5 & 19 & 11 & 4 & 5 & 6 & 38 & 148 & 239 \\
\hline Malaysia & 2 & 14 & 12 & 4 & 10 & 12 & 4 & 5 & 0 & 27 & 90 & 757 \\
\hline Singapore & 1 & 5 & 24 & 0 & 5 & 20 & 2 & 0 & 9 & 30 & 96 & 355 \\
\hline South Africa & 9 & 2 & 7 & 3 & 5 & 11 & 2 & 0 & 3 & 23 & 65 & 668 \\
\hline South Korea & 2 & 15 & 20 & 7 & 10 & 11 & 4 & 1 & 4 & 22 & 96 & 725 \\
\hline Thailand & 1 & 8 & 2 & 0 & 4 & 8 & 5 & 2 & 2 & 18 & 50 & 392 \\
\hline Philippines & 4 & 1 & 4 & 0 & 6 & 5 & 4 & 2 & 0 & 21 & 47 & 226 \\
\hline Taiwan & 0 & 5 & 19 & 5 & 1 & 3 & 0 & 0 & 21 & 16 & 70 & 462 \\
\hline Greece & 2 & 5 & 2 & 1 & 3 & 7 & 2 & 0 & 6 & 15 & 43 & 281 \\
\hline Portugal & 0 & 10 & 2 & 1 & 2 & 9 & 6 & 1 & 1 & 15 & 47 & 125 \\
\hline Argentina & 2 & 13 & 5 & 2 & 8 & 2 & 1 & 5 & 0 & 10 & 48 & 129 \\
\hline Mexico & 1 & 18 & 8 & 3 & 17 & 22 & 5 & 0 & 0 & 13 & 87 & 188 \\
\hline Turkey & 3 & 5 & 12 & 6 & 1 & 2 & 4 & 3 & 1 & 8 & 45 & 285 \\
\hline Finland & 1 & 7 & 10 & 1 & 4 & 6 & 7 & 0 & 6 & 5 & 47 & 147 \\
\hline Chile & 2 & 7 & 4 & 0 & 6 & 5 & 5 & 12 & 0 & 8 & 49 & 285 \\
\hline India & 6 & 10 & 14 & 7 & 23 & 3 & 3 & 2 & 19 & 9 & 96 & 5863 \\
\hline Indonesia & 3 & 9 & 2 & 7 & 7 & 6 & 2 & 0 & 0 & 12 & 48 & 277 \\
\hline Peru & 13 & 5 & 1 & 2 & 9 & 1 & 1 & 3 & 0 & 9 & 44 & 242 \\
\hline Luxemburg & 0 & 2 & 0 & 0 & 5 & 4 & 2 & 3 & 0 & 15 & 31 & 51 \\
\hline Colombia & 1 & 11 & 0 & 3 & 7 & 4 & 3 & 1 & 0 & 16 & 46 & 145 \\
\hline Poland & 3 & 7 & 3 & 0 & 10 & 6 & 1 & 0 & 2 & 14 & 46 & 221 \\
\hline China & 3 & 11 & 10 & 5 & 2 & 4 & 3 & 7 & 2 & 1 & 48 & 950 \\
\hline Total & 224 & 588 & 693 & 272 & 588 & 932 & 257 & 195 & 589 & 1169 & 5507 & 35044 \\
\hline
\end{tabular}


Table 1B. Data on Market Capitalization in Billions of US Dollars by Country and Industry, December 1999

\begin{tabular}{|c|c|c|c|c|c|c|c|c|c|c|c|c|}
\hline & Res & Bas & Gen & $\mathrm{Cgd}$ & Ngd & Csr & Nsr & Utì & It & Fin & Tot & IFC \\
\hline United States & 568 & 312 & 1100 & 209 & 2012 & 1749 & 1141 & 316 & 4659 & 1949 & 14015 & 16635 \\
\hline United Kingdom & 349 & 76 & 85 & 15 & 383 & 398 & 463 & 103 & 162 & 594 & 2626 & 2933 \\
\hline France & 101 & 85 & 137 & 102 & 171 & 137 & 218 & 0 & 134 & 169 & 1253 & 1475 \\
\hline Germany & 0 & 96 & 182 & 134 & 41 & 60 & 225 & 23 & 74 & 320 & 1157 & 1432 \\
\hline Italy & 46 & 7 & 18 & 31 & 6 & 68 & 213 & 70 & 2 & 248 & 709 & 728 \\
\hline Japan & 14 & 236 & 501 & 534 & 290 & 549 & 927 & 111 & 857 & 699 & 4717 & 4547 \\
\hline Canada & 71 & 43 & 43 & 4 & 17 & 83 & 85 & 20 & 156 & 109 & 630 & 801 \\
\hline Australia & 58 & 9 & 8 & 1 & 18 & 81 & 95 & 3 & 8 & 118 & 399 & 428 \\
\hline Austria & 3 & 5 & 2 & 0 & 2 & 2 & 0 & 4 & 0 & 13 & 31 & 33 \\
\hline Belgium & 0 & 15 & 18 & 1 & 9 & 7 & 12 & 23 & 2 & 88 & 176 & 185 \\
\hline Denmark & 0 & 1 & 4 & 1 & 19 & 31 & 18 & 0 & 2 & 12 & 88 & 105 \\
\hline Hong Kong SAR & 1 & 7 & 97 & 4 & 3 & 31 & 91 & 23 & 30 & 256 & 542 & 609 \\
\hline Ireland & 1 & 10 & 0 & 1 & 14 & 10 & 0 & 0 & 10 & 22 & 68 & 42 \\
\hline Netherlands & 145 & 23 & 53 & 12 & 64 & 65 & 102 & 0 & 38 & 233 & 736 & 695 \\
\hline New Zealand & 1 & 4 & 0 & 0 & 2 & 5 & 8 & 3 & 0 & 3 & 26 & 28 \\
\hline Norway & 16 & 4 & 7 & 1 & 4 & 14 & 2 & 0 & 2 & 10 & 60 & 64 \\
\hline Spain & 29 & 22 & 7 & 0 & 8 & 33 & 89 & 54 & 15 & 104 & 361 & 432 \\
\hline Sweden & 0 & 19 & 42 & 9 & 4 & 38 & 14 & 4 & 140 & 60 & 329 & 373 \\
\hline Switzerland & 0 & 34 & 65 & 22 & 312 & 22 & 32 & 3 & 2 & 214 & 708 & 693 \\
\hline Malaysia & 1 & 9 & 10 & 2 & 8 & 16 & 13 & 14 & 0 & 26 & 100 & 145 \\
\hline Singapore & 0 & 7 & 22 & 0 & 3 & 31 & 32 & 0 & 11 & 67 & 174 & 198 \\
\hline South Africa & 36 & 3 & 13 & 3 & 8 & 11 & 5 & 0 & 5 & 52 & 137 & 262 \\
\hline South Korea & 5 & 20 & 69 & 8 & 8 & 7 & 90 & 19 & 8 & 32 & 267 & 309 \\
\hline Thailand & 2 & 6 & 1 & 0 & 1 & 6 & 7 & 1 & 3 & 21 & 47 & 58 \\
\hline Philippines & 1 & 1 & 4 & 0 & 3 & 2 & 4 & 2 & 0 & 15 & 31 & 48 \\
\hline Taiwan & 0 & 27 & 46 & 15 & 2 & 5 & 0 & 0 & 162 & 54 & 311 & 376 \\
\hline Greece & 5 & 10 & 3 & 1 & 6 & 13 & 19 & 0 & 11 & 49 & 116 & 204 \\
\hline Portugal & 0 & 6 & 0 & 0 & 1 & 8 & 24 & 10 & 0 & 21 & 70 & 66 \\
\hline Argentina & 1 & 6 & 2 & 0 & 2 & 0 & 7 & 3 & 0 & 10 & 32 & 84 \\
\hline Mexico & 3 & 22 & 10 & 1 & 17 & 30 & 40 & 0 & 0 & 16 & 138 & 154 \\
\hline Turkey & 19 & 4 & 25 & 4 & 1 & 5 & 4 & 2 & 0 & 36 & 100 & 113 \\
\hline Finland & 4 & 29 & 8 & 1 & 3 & 5 & 55 & 0 & 216 & 6 & 327 & 349 \\
\hline Chile & 1 & 4 & 7 & 0 & 5 & 4 & 7 & 14 & 0 & 8 & 50 & 68 \\
\hline India & 18 & 8 & 39 & 6 & 19 & 10 & 8 & 2 & 27 & 8 & 144 & 185 \\
\hline Indonesia & 1 & 5 & 1 & 3 & 12 & 2 & 8 & 0 & 0 & 20 & 50 & 64 \\
\hline Peru & 2 & 1 & 0 & 0 & I & 0 & 0 & 1 & 0 & 2 & 6 & 13 \\
\hline Luxemburg & 0 & 1 & 0 & 0 & 2 & 6 & 2 & 0 & 0 & 10 & 22 & 36 \\
\hline Colombia & 0 & 1 & 0 & 0 & 2 & 0 & 0 & 0 & 0 & 2 & 6 & 12 \\
\hline Poland & 4 & 1 & 1 & 0 & 1 & 1 & 9 & 0 & 1 & 8 & 25 & 30 \\
\hline China & 4 & 14 & 15 & 7 & 3 & 6 & 3 & 9 & 2 & 3 & 66 & 331 \\
\hline Total & 1508 & 1190 & 2644 & 1131 & 3486 & 3549 & 4073 & 838 & 6739 & 5690 & 30849 & 35346 \\
\hline
\end{tabular}


Table 1C. Data on Market Capitalization in Percentage of the Sample Total by Country and Industry, December 1999

\begin{tabular}{|c|c|c|c|c|c|c|c|c|c|c|c|}
\hline & Res & Bas & Gen & Cgd & Ngd & Csr & Nsr & Utl & It & Fin & Tot \\
\hline United States & 1.84 & 1.01 & 3.57 & 0.68 & 6.52 & 5.67 & 3.70 & 1.03 & 15.10 & 6.32 & 45.43 \\
\hline United Kingdom & 1.13 & 0.25 & 0.28 & 0.05 & 1.24 & 1.29 & 1.50 & 0.33 & 0.52 & 1.93 & 8.51 \\
\hline France & 0.33 & 0.28 & 0.44 & 0.33 & 0.55 & 0.44 & 0.71 & 0.00 & 0.43 & 0.55 & 4.06 \\
\hline Germany & 0.00 & 0.31 & 0.59 & 0.44 & 0.13 & 0.19 & 0.73 & 0.08 & 0.24 & 1.04 & 3.75 \\
\hline Italy & 0.15 & 0.02 & 0.06 & 0.10 & 0.02 & 0.22 & 0.69 & 0.23 & 0.01 & 0.80 & 2.30 \\
\hline Japan & 0.05 & 0.76 & 1.62 & 1.73 & 0.94 & 1.78 & 3.00 & 0.36 & 2.78 & 2.27 & 15.29 \\
\hline Canada & 0.23 & 0.14 & 0.14 & 0.01 & 0.05 & 0.27 & 0.28 & 0.06 & 0.50 & 0.35 & 2.04 \\
\hline Australia & 0.19 & 0.03 & 0.03 & 0.00 & 0.06 & 0.26 & 0.31 & 0.01 & 0.03 & 0.38 & 1.29 \\
\hline Austria & 0.01 & 0.02 & 0.01 & 0.00 & 0.01 & 0.01 & 0.00 & 0.01 & 0.00 & 0.04 & 0.10 \\
\hline Belgium & 0.00 & 0.05 & 0.06 & 0.00 & 0.03 & 0.02 & 0.04 & 0.07 & 0.01 & 0.29 & 0.57 \\
\hline Denmark & 0.00 & 0.00 & 0.01 & 0.00 & 0.06 & 0.10 & 0.06 & 0.00 & 0.01 & 0.04 & 0.29 \\
\hline Hong Kong SAR & 0.00 & 0.02 & 0.31 & 0.01 & 0.01 & 0.10 & 0.30 & 0.07 & 0.10 & 0.83 & 1.76 \\
\hline Ireland & 0.00 & 0.03 & 0,00 & 0.00 & 0.05 & 0.03 & 0.00 & 0.00 & 0.03 & 0.07 & 0.22 \\
\hline Netherlands & 0.47 & 0.08 & 0.17 & 0.04 & 0.21 & 0.21 & 0.33 & 0.00 & 0.12 & 0.75 & 2.38 \\
\hline New Zealand & 0.00 & 0.01 & 0.00 & 0.00 & 0.01 & 0.02 & 0.03 & 0.01 & 0.00 & 0.01 & 0.08 \\
\hline Norway & 0.05 & 0.01 & 0.02 & 0.00 & 0.01 & 0.05 & 0.01 & 0.00 & 0.01 & 0.03 & 0.19 \\
\hline Spain & 0.09 & 0.07 & 0.02 & 0.00 & 0.03 & 0.11 & 0.29 & 0.17 & 0.05 & 0.34 & 1.17 \\
\hline Sweden & 0.00 & 0.06 & 0.14 & 0.03 & 0.01 & 0.12 & 0.05 & 0.01 & 0.45 & 0.20 & 1.07 \\
\hline Switzerland & 0.00 & 0.11 & 0.21 & 0.07 & 1.01 & 0.07 & 0.10 & 0.01 & 0.01 & 0.69 & 2.29 \\
\hline Malaysia & 0.00 & 0.03 & 0.03 & 0.01 & 0.03 & 0.05 & 0.04 & 0.05 & 0.00 & 0.08 & 0.32 \\
\hline Singapore & 0.00 & 0.02 & 0.07 & 0.00 & 0.01 & 0.10 & 0.10 & 0.00 & 0.04 & 0.22 & 0.56 \\
\hline South Africa & 0.12 & 0.01 & 0.04 & 0.01 & 0.03 & 0.04 & 0.02 & 0.00 & 0.02 & 0.17 & 0.44 \\
\hline South Korea & 0.02 & 0.06 & 0.22 & 0.03 & 0.03 & 0.02 & 0.29 & 0.06 & 0.03 & 0.10 & 0.86 \\
\hline Thailand & 0.01 & 0.02 & 0.00 & 0.00 & 0.00 & 0.02 & 0.02 & 0.00 & 0.01 & 0.07 & 0.15 \\
\hline Philippines & 0.00 & 0.00 & 0.01 & 0.00 & 0.01 & 0.01 & 0.01 & 0.01 & 0.00 & 0.05 & 0.10 \\
\hline Taiwan & 0.00 & 0.09 & 0.15 & 0.05 & 0.01 & 0.02 & 0.00 & 0.00 & 0.52 & 0.18 & 1.01 \\
\hline Greece & 0.02 & 0.03 & 0.01 & 0.00 & 0.02 & 0.04 & 0.06 & 0.00 & 0.04 & 0.16 & 0.38 \\
\hline Portugal & 0.00 & 0.02 & 0.00 & 0.00 & 0.00 & 0.02 & 0.08 & 0.03 & 0.00 & 0.07 & 0.23 \\
\hline Argentina & 0.00 & 0.02 & 0.01 & 0.00 & 0.01 & 0.00 & 0.02 & 0.01 & 0.00 & 0.03 & 0.10 \\
\hline Mexico & 0.01 & 0.07 & 0.03 & 0.00 & 0.06 & 0.10 & 0.1 & 0.00 & 0.00 & 0.05 & 0.45 \\
\hline Turkey & 0.06 & 0.01 & 0.08 & 0.01 & 0.00 & 0.02 & 0.01 & 0.01 & $0: 00$ & 0.12 & 0.32 \\
\hline Finland & 0.01 & 0.09 & 0.03 & 0.00 & 0.01 & 0.02 & 0.18 & 0.00 & 0.70 & 0.02 & 1.06 \\
\hline Chile & 0.00 & 0.01 & 0.02 & 0.00 & 0.02 & 0.01 & 0.02 & 0.05 & 0.00 & 0.03 & 0.16 \\
\hline India & 0.06 & 0.03 & 0.13 & 0.02 & 0.06 & 0.03 & 0.03 & 0.01 & 0.09 & 0.03 & 0.47 \\
\hline Indonesia & 0.00 & 0.02 & 0.00 & 0.01 & 0.04 & 0.01 & 0.02 & 0.00 & 0.00 & 0.06 & 0.16 \\
\hline Peru & 0.01 & 0.00 & 0.00 & 0.00 & 0.00 & 0.00 & 0.00 & 0.00 & 0.00 & 0.01 & 0.02 \\
\hline Luxemburg & 0.00 & 0.00 & 0.00 & 0.00 & 0.01 & 0.02 & 0.01 & 0.00 & 0.00 & 0.03 & 0.07 \\
\hline Colombia & 0.00 & 0.00 & 0.00 & 0.00 & 0.01 & 0.00 & 0.00 & 0.00 & 0.00 & 0.01 & 0.02 \\
\hline Poland & 0.01 & 0.00 & 0.00 & 0.00 & 0.00 & 0.00 & 0.03 & 0.00 & 0.00 & 0.03 & 0.08 \\
\hline China & 0.01 & 0.05 & 0.05 & 0.02 & 0.01 & 0.02 & 0.01 & 0.03 & 0.01 & 0.01 & 0.21 \\
\hline Total & 4.89 & 3.86 & 8.57 & 3.67 & 11.30 & 11.50 & 13.20 & 2.72 & 21.85 & 18.451 & 100.00 \\
\hline
\end{tabular}


Table 2: Average $\mathrm{R}^{2}$ for Each Model

\section{Developed Countries only}

$3: 1986$ to $8 \cdot 2000 \quad 3: 1986$ to $8: 1988$

$9: 1988$ to $8: 1991$

$9: 1991$ to $8: 1994$

$9: 1994$ to $8: 1997$

$9: 1997$ to $8: 2000$

a. Equal-Weighted Model

$\mathrm{R}^{2}$ country-factor only

$\mathrm{R}^{2}$ country+industry factors

0.15

0.18

0.22

b. Value-Weighted Model

$\mathrm{R}^{2}$ country-factor only

0.16

$\mathrm{R}^{2}$ country+industry factors

$\mathrm{R}^{2}$ country+industry+ size factors

0.35

0.36

0.17

0.40

0.42

\section{All Countries}

$3: 1986$ to $8: 2000$

$3: 1986$ to $8: 1988$

$9: 1988$ to $8: 1991$
$9: 1991$ to $8: 1994$

9:1994 to $8: 1997$

0.12

0.16

0.20

0.19

0.13

0.15

0.32

0.33

0.09

0.28

0.29

0.40

0.38

\section{a. Equal-Weighted Model}

$\mathrm{R}^{2}$ country-factor only

$\mathrm{R}^{2}$ country+industry factors

\section{b. Value-Weighted Model}

$\mathrm{R}^{2}$ country-factor only

$\mathrm{R}^{2}$ country+industry factors

$R^{2}$ country+industry+size factors

\subsection{1}

0.23

0.21

0.37

0.38
0.21

0.24

0.20

0.42

0.43
0.25

0.27

0.24

0.25

0.30

0.41

0.41

0.24

0.43
0.16

0.18

0.18

0.21

0.42
0.20

0.34

0.35
0.13

0.30 
Table 3: Value-Weighted \$ Returns Model: FTSE Industry Effects - Industrialized Countries

(US Dollar returns in percentage per month)

\begin{tabular}{|c|c|c|c|c|c|c|c|c|c|c|c|c|c|c|c|c|c|c|}
\hline & \multicolumn{3}{|c|}{$3: 1986$ to $8: 2000$} & \multicolumn{3}{|c|}{$3: 1986$ to $8: 1988$} & \multicolumn{3}{|c|}{$9: 1988$ to $8: 1991$} & \multicolumn{3}{|c|}{$9: 1991$ to $8: 1994$} & \multicolumn{3}{|c|}{$9: 1994$ to $8: 1997$} & \multicolumn{3}{|c|}{$9: 1997$ to $8: 2000$} \\
\hline & Mean & St Dev & Sharpe & Mean & St Dev & Sharpe & Mean & St Dev & Sharpe & Mean & St Dev & Sharpe & Mean & St Dev & Sharpe & Mean & St Dev & Sharpe \\
\hline Resources & -0.34 & 3.78 & -0.09 & 0.61 & 3.31 & 0.18 & 0.00 & 3.17 & 0.00 & -0.28 & 2.27 & -0.12 & -0.19 & 2.07 & -0.09 & -1.69 & 6.26 & -0.27 \\
\hline Basic Industries & -0.48 & 2.67 & -0.18 & 0.33 & 2.39 & 0.14 & -0.07 & 2.24 & -0.03 & 0.05 & 1.61 & 0.03 & -0.66 & 1.19 & -0.56 & -1.92 & 4.29 & -0.45 \\
\hline General Industries & -0.06 & 1.99 & -0.03 & -0.34 & 3.36 & -0.10 & 0.17 & 1.68 & 0.10 & 0.12 & 1.52 & 0.08 & -0.02 & 0.77 & -0.02 & -0.27 & 2.07 & -0.13 \\
\hline Cyclical Consumer Goods & -0.16 & 3.07 & -0.05 & 0.07 & 4.46 & 0.02 & -0.35 & 2.04 & -0.17 & 0.38 & 2.40 & 0.16 & 0.17 & 1.68 & 0.10 & -1.02 & 4.01 & -0.25 \\
\hline Non-Cyclical Consumer Goods & -0.15 & 2.43 & -0.06 & -0.06 & 2.36 & -0.02 & 0.56 & 1.50 & 0.37 & -0.47 & 1.91 & -0.25 & 0.13 & 1.44 & 0.09 & -0.88 & 3.91 & -0.23 \\
\hline Cyclical Services & -0.11 & 1.50 & -0.07 & -0.19 & 2.27 & -0.08 & 0.24 & 1.07 & 0.22 & 0.06 & 1.05 & 0.06 & -0.34 & 1.14 & -0.29 & -0.31 & 1.73 & -0.18 \\
\hline Non-Cyclical Services & -0.24 & 3.55 & -0.07 & -0.41 & 6.05 & -0.07 & -0.98 & 3.02 & -0.33 & 0.16 & 1.94 & 0.08 & -0.38 & 1.75 & -0.22 & 0.38 & 3.84 & 0.10 \\
\hline Utilities & -0.62 & 4.32 & -0.14 & -0.49 & 7.01 & -0.07 & -0.08 & 3.18 & -0.02 & -0.33 & 1.98 & -0.17 & -0.89 & 2.03 & -0.44 & -1.27 & 5.73 & -0.22 \\
\hline Information Technology & 0.93 & 4.62 & 0.20 & -0.37 & 5.02 & -0.07 & -0.46 & 3.20 & -0.14 & 0.84 & 2.11 & 0.40 & 1.41 & 3.85 & 0.37 & 2.99 & 6.86 & 0.44 \\
\hline Financials & -0.18 & 2.92 & -0.06 & 0.04 & 4.19 & 0.01 & -0.06 & 1.98 & -0.03 & -0.02 & 1.69 & -0.01 & 0.04 & 1.30 & 0.03 & -0.86 & 4.30 & -0.20 \\
\hline $\begin{array}{l}\text { Average Abs. Industry Effect } \\
\text { Dispersion of Risk-Adjusted }\end{array}$ & 0.33 & 3.08 & & 0.29 & 4,04 & & 0.30 & 2.31 & & 0.27 & 1.85 & & 0.42 & 1.72 & & 1.16 & 4.30 & \\
\hline Industry Premia & & & 0.10 & & & 0.10 & & & 0.20 & & & 0.18 & & & 0.28 & & & 0.24 \\
\hline Global Factor & 2.00 & 4.56 & 0.44 & 2.89 & 5.27 & 0.55 & 1.22 & 5.58 & 0.22 & 1.51 & 3.56 & 0.42 & 1.61 & 3.07 & 0.52 & 2.93 & 4.91 & 0.60 \\
\hline United States & 0.04 & 3.44 & 0.01 & -1.54 & 4.40 & -0.35 & 0.72 & 4.62 & 0.16 & -0.22 & 3.25 & -0.07 & 0.88 & 1.85 & 0.48 & 0.09 & 1.95 & 0.05 \\
\hline United Kingdom & 0.01 & 3.44 & 0.00 & -0.93 & 4.75 & -0.19 & 0.85 & 3.99 & 0.21 & -0.10 & 3.57 & -0.03 & 0.37 & 2.20 & 0.17 & -0.31 & 2.12 & -0.15 \\
\hline France & 0.05 & 4.45 & 0.01 & -0.78 & 6.97 & -0.11 & 0.74 & 4.27 & 0.17 & -0.04 & 3.82 & -0.01 & -0.32 & 3.24 & -0.10 & 0.50 & 3.60 & 0.14 \\
\hline Germany & -0.42 & 4.97 & -0.08 & -2.40 & 6.75 & -0.36 & 0.74 & 5.77 & 0.13 & -0.25 & 4.23 & -0.06 & -0.09 & 3.43 & -0.03 & -0.42 & 4.04 & -0.10 \\
\hline Italy & -0.34 & 6.89 & -0.05 & -1.78 & 7.68 & -0.23 & -0.11 & 4.97 & -0.02 & -0.52 & 8.05 & -0.06 & -0.46 & 5.68 & -0.08 & 0.94 & 7.76 & 0.12 \\
\hline Japan & -0.27 & 4.67 & -0.06 & 1.82 & 4.31 & 0.42 & -0.88 & 4.19 & -0.21 & 0.02 & 5.00 & 0.00 & -1.72 & 3.62 & -0.47 & -0.25 & 5.53 & -0.04 \\
\hline Canada & -0.11 & 3.91 & $-0,03$ & -1.24 & 4.46 & -0.28 & 0.14 & 4.78 & 0.03 & -0.65 & 3.91 & -0.17 & 0.63 & 2.79 & 0.22 & 0.37 & 3.33 & 0.11 \\
\hline Australia & -0.04 & 5.98 & -0.01 & 0.79 & 10.58 & 0.07 & -0.01 & 6.09 & 0.00 & 0.04 & 4.72 & 0.01 & -0.10 & 3.06 & -0.03 & -0.79 & 3.75 & -0.21 \\
\hline Austria & -0.39 & 7.01 & 0.06 & -2.49 & 9.78 & -0.25 & 2.93 & 9.38 & 0.31 & -0.60 & 5.56 & -0.11 & -0.77 & 3.19 & -0.24 & -1.38 & 4.28 & -0.32 \\
\hline Beigium & -0.20 & 4.40 & -0.05 & -0.54 & 5.42 & -0.10 & 0.03 & 4.70 & 0.01 & 0.04 & 4.00 & 0.01 & 0.10 & 2.18 & 0.05 & -0.68 & 5.28 & -0.13 \\
\hline Denmark & -0.09 & 5.01 & -0.02 & -1.70 & 6.01 & -0.28 & 1.52 & 6.05 & 0.25 & -0.52 & 4.38 & -0.12 & 0.35 & 3.15 & 0.11 & -0.39 & 4.82 & -0.08 \\
\hline Hong Kong & 0.95 & 8.53 & 0.11 & 0.01 & 10.58 & 0.00 & 1.13 & 5.90 & 0.19 & 2.17 & 9.11 & 0.24 & 0.74 & 5.41 & 0.14 & 0.53 & 10.81 & 0.05 \\
\hline Ireland & 0.33 & 5.34 & 0.06 & 0.25 & 8.12 & 0.03 & 0.22 & 4.83 & 0.05 & 0.58 & 4.85 & 0.12 & 0.72 & 2.34 & 0.31 & -0.14 & 5.77 & -0.02 \\
\hline Netherlands & -0.02 & 3.32 & 0.00 & -1.46 & 3.62 & -0.40 & 0.20 & 3.33 & 0.06 & 0.43 & 3.02 & 0.14 & 0.73 & 1.93 & 0.38 & -0.21 & 4.12 & -0.05 \\
\hline New Zealand & -0.63 & 7.90 & -0.08 & -1.99 & 14.59 & -0.14 & -0.40 & 7.44 & -0.05 & 1.19 & 5.06 & 0.24 & 0.18 & 3.68 & 0.05 & -2.36 & 5.38 & -0.44 \\
\hline Norway & 0.36 & 6.15 & 0.06 & -0.52 & 7.16 & -0.07 & 1.56 & 7.04 & 0.22 & 0.21 & 6.22 & 0.03 & 0.73 & 3.86 & 0.19 & -0.33 & 6.20 & -0.05 \\
\hline Spain & 0.91 & 7.19 & 0.13 & 4.30 & 13.25 & 0.32 & 0.28 & 4.49 & 0.06 & -0.33 & 5.72 & -0.06 & 0.85 & 3.73 & 0.23 & 0.02 & 5.54 & 0.00 \\
\hline Sweden & 0.21 & 5.57 & 0.04 & -0.57 & 6.50 & -0.09 & 0.64 & 4.96 & 0.13 & 0.12 & 6.67 & 0.02 & 1.21 & 4.47 & 0.27 & -0.47 & 5.20 & -0.09 \\
\hline Switzerland & -0.04 & 4.01 & -0.01 & -1.54 & 5.02 & -0.31 & 0.34 & 3.93 & 0.09 & 0.98 & 3.99 & 0.25 & 0.22 & 3.44 & 0.06 & -0.43 & 3.46 & -0.13 \\
\hline Greece & 1.51 & 13.50 & 0.11 & -1.04 & 3.55 & -0.29 & 5.98 & 22.31 & 0.27 & -1.56 & 8.48 & -0.18 & 1.17 & 5.81 & 0.20 & 0.94 & 11.98 & 0.08 \\
\hline Portugal & -0.09 & 6.40 & -0.01 & -3.69 & 6.71 & -0.55 & 0.22 & 7.16 & 0.03 & 0.09 & 5.89 & 0.01 & 0.43 & 4.25 & 0.10 & -0.39 & 7.78 & -0.05 \\
\hline Finland & 0.25 & 6.78 & 0.04 & 0.28 & 4.26 & 0.06 & -1.69 & 7.12 & -0.24 & 1.59 & 7.93 & 0.20 & 0.38 & 5.32 & 0.07 & 0.73 & 6.66 & 0.11 \\
\hline Luxembourg & 0.22 & 5.21 & 0.04 & & & & & & & 1.00 & 4.65 & 0.21 & -0.48 & 3.69 & -0.13 & 0.25 & 6.78 & 0.04 \\
\hline Average Abs. Country Effect & 0.32 & 5.83 & & 1.44 & 7.02 & & 0.97 & 6.24 & & 0.58 & 5.31 & & 0.59 & 3.58 & & 0.56 & 5.48 & \\
\hline w/o Greece and Flong Kong & 0.24 & 5.34 & & 1.53 & 7.02 & & 0.71 & 5.45 & & 0.45 & 4.98 & & 0.56 & 3.39 & & 0.55 & 4.92 & \\
\hline Dispersion of Risk-Adjusted & & & & & & & & & & & & & & & & & & \\
\hline Country Premia & & & 0.06 & & & 0.23 & & & 0.14 & & & 0.13 & & & 0.21 & & & 0.14 \\
\hline
\end{tabular}


Table 4. Value-Weighted Percentage Returns Model: FTSE Industry Effects (US dollar returns in percentage per month)

\begin{tabular}{|c|c|c|c|c|c|c|c|c|c|c|c|c|c|c|c|c|c|c|}
\hline & \multicolumn{3}{|c|}{$3: 1986$ to $8: 2000$} & \multicolumn{3}{|c|}{$3: 1986$ to $8: 1988$} & \multicolumn{3}{|c|}{$9: 1988$ to $8: 1991$} & \multicolumn{3}{|c|}{$9: 1991$ to $8: 1994$} & \multicolumn{3}{|c|}{$9: 1994$ to $8: 1997$} & \multicolumn{3}{|c|}{$9: 1997$ to $8: 2000$} \\
\hline & Mean & St Dev & Sharpe & Mean & St Dev & Sharpe & Mean & St Dev & Sharpe & Mean & St Dev & Sharpe & Mean & St Dev & Sharpe & Mean & St Dev & Sharpe \\
\hline Resources & -0.35 & 3.67 & -0.10 & 0.57 & 3.20 & 0.18 & $-0,04$ & 3.05 & -0.01 & -0.25 & 2.16 & -0.11 & -0.21 & 2.00 & -0.10 & -1.67 & 6.12 & -0.27 \\
\hline Basic Industries & -0.48 & 2.54 & -0.19 & 0.30 & 2.34 & 0.13 & -0.09 & 2.15 & -0.04 & 0.02 & 1.49 & 0.01 & -0.69 & 1.07 & -0.64 & -1.79 & 4.07 & -0.44 \\
\hline General Industries & -0.03 & 1.93 & -0.01 & -0.32 & 3.29 & -0.10 & 0.21 & 1.64 & 0.13 & 0.08 & 1.42 & 0.06 & 0.03 & 0.71 & 0.04 & -0.19 & 2.01 & -0.09 \\
\hline Cyclical Consumer Goods & -0.19 & 2.97 & -0.06 & 0.03 & 4.40 & 0.01 & -0.31 & 2.02 & -0.16 & 0.23 & 2.24 & 0.10 & 0.16 & 1.61 & 0.10 & -1.01 & 3.87 & -0.26 \\
\hline Non-Cyclical Consumer Goods & -0.14 & 2.38 & -0.06 & -0.06 & 2.33 & -0.02 & 0.53 & 1.47 & 0.36 & -0.42 & 1.84 & -0.23 & 0.12 & 1.40 & 0.09 & -0.87 & 3.85 & -0.23 \\
\hline Cyclical Services & -0.10 & 1.47 & -0.07 & -0.20 & 2,24 & -0.09 & 0.24 & 1.04 & 0.23 & 0.05 & 1.02 & 0.05 & -0.32 & 1.09 & $-0,29$ & -0.29 & 1.73 & -0.17 \\
\hline Non-Cyclical Services & -0.27 & 3.50 & -0.08 & -0.41 & 6.05 & -0.07 & -0.95 & 3.00 & -0.32 & 0.05 & 1.82 & 0.03 & -0.43 & 1.57 & -0.28 & 0.39 & 3.81 & 0.10 \\
\hline Utilities & -0.61 & 4.26 & -0.14 & -0.49 & 7.01 & -0.07 & -0.07 & 3.12 & -0.02 & -0.32 & 1.88 & -0.17 & -0.83 & 1.91 & -0.43 & -1.31 & 5.56 & -0.24 \\
\hline Information Technology & 0.95 & 4.59 & 0.21 & -0.38 & 5.01 & -0.07 & -0.43 & 3.18 & -0.14 & 0.87 & 2.12 & 0.41 & 1.47 & 3.80 & 0.39 & 3.00 & 6.80 & 0.44 \\
\hline Financials & -0.16 & 2.83 & -0.06 & 0.07 & 4.14 & 0.02 & -0.06 & 1.93 & -0.03 & 0.04 & 1.60 & 0.03 & 0.06 & 1.15 & 0.05 & -0.86 & 4.15 & -0.21 \\
\hline $\begin{array}{l}\text { Average Abs. Industry Effect } \\
\text { Dispersion of Risk-Adjusted }\end{array}$ & 0.33 & 3.01 & & 0.28 & 4.00 & & 0.29 & 2.26 & & 0.23 & 1.76 & & 0.43 & 1.63 & & 1.14 & 4.20 & \\
\hline Industry P'remia & & & 0.10 & & & 0.09 & & & 0.20 & & & 0.18 & & & 0.30 & & & 0.25 \\
\hline Global Factor & 2.04 & 4.51 & 0.45 & 2.94 & 5.23 & 0.56 & 1.28 & 5.44 & 0.24 & 1.67 & 3.42 & 0.49 & 1.56 & 3.04 & 0.51 & 2.92 & 5.00 & 0.58 \\
\hline United States & -0.01 & 3.40 & 0.00 & -1.58 & 4.35 & -0.36 & 0.67 & 4.53 & 0.15 & -0.39 & 3.13 & -0.12 & 0.92 & 1.88 & 0.49 & 0.10 & 2.01 & 0.05 \\
\hline United Kingdom & -0.03 & 3.41 & -0.01 & -0.97 & 4.74 & -0.20 & 0.80 & 3.95 & 0.20 & -0.26 & 3.41 & -0.08 & 0.42 & 2.23 & 0.19 & -0.32 & 2.21 & -0.14 \\
\hline France & 0.00 & 4.43 & 0.00 & -0.82 & 6.96 & -0.12 & 0.68 & 4.30 & 0.16 & -0.18 & 3.70 & -0.05 & -0.28 & 3.14 & -0.09 & 0.49 & 3.68 & 0.13 \\
\hline Germany & -0.47 & 4.91 & -0.10 & -2.45 & 6.73 & -0.36 & 0.68 & 5.70 & 0.12 & -0.41 & 4.04 & -0.10 & -0.06 & 3.41 & -0.02 & -0.44 & 4.05 & -0.11 \\
\hline Italy & -0.39 & 6.86 & -0.06 & -1.83 & 7.68 & -0.24 & -0.18 & 4.96 & -0.04 & -0.68 & 7.98 & -0.09 & -0.42 & 5.60 & -0.07 & 0.94 & 7.76 & 0.12 \\
\hline Japan & -0.32 & 4.76 & -0.07 & 1.77 & 4.38 & 0.40 & -0.94 & 4.29 & -0.22 & -0.13 & 5.28 & -0.03 & -1.68 & 3.69 & -0.46 & -0.26 & 5.47 & -0.05 \\
\hline Canada & -0.16 & 3.83 & -0.04 & -1.27 & 4.41 & -0.29 & 0.08 & 4.69 & 0.02 & -0.82 & 3.69 & -0.22 & 0.67 & 2.71 & 0.25 & 0.37 & 3.29 & 0.11 \\
\hline Australia & -0.08 & 5.90 & -0.01 & 0.75 & 10.52 & 0.07 & -0.05 & 6.02 & -0.01 & -0.14 & 4.52 & -0.03 & -0.06 & 3.02 & -0.02 & -0.79 & 3.65 & $-0,22$ \\
\hline Austria & -0.45 & 6.91 & -0.06 & -2.53 & 9.71 & -0.26 & 2.88 & 9.21 & 0.31 & -0.80 & 5.36 & -0.15 & -0.74 & 3.12 & -0.24 & -1.40 & 4.28 & -0.33 \\
\hline Belgium & -0.25 & 4.37 & -0.06 & -0.59 & 5.38 & -0.11 & -0.04 & 4.62 & -0.01 & -0.12 & 3.82 & -0.03 & 0.13 & 2.14 & 0.06 & -0.69 & 5.44 & -0.13 \\
\hline Denmark & -0.14 & 5.00 & -0.03 & -1.75 & 5.99 & -0.29 & 1.46 & 5.98 & 0.24 & -0.70 & 4.36 & -0.16 & 0.40 & 3.12 & 0.13 & -0.40 & 4.89 & -0.08 \\
\hline Hong Kong SAR & 0.89 & 8.36 & 0.11 & -0.05 & 10.55 & 0.00 & 1.06 & 5.91 & 0.18 & 1.98 & 8.74 & 0.23 & 0.77 & 5.30 & 0.14 & 0.53 & 10.58 & 0.05 \\
\hline Ireland & 0.28 & 5.29 & 0.05 & 0.21 & 8.09 & 0.03 & 0.17 & 4.72 & 0.04 & 0.39 & 4.77 & 0.08 & 0.76 & 2.29 & 0.33 & -0.16 & 5.80 & -0.03 \\
\hline Netherlands & -0.06 & 3.28 & -0.02 & -1.50 & 3.58 & -0.42 & 0.16 & 3.27 & 0.05 & 0.24 & 2.87 & 0.08 & 0.77 & 1.93 & 0.40 & -0.22 & 4.15 & -0.05 \\
\hline New Zealand & -0.67 & 7.86 & -0.08 & -2.04 & 14.56 & -0.14 & -0.45 & 7.44 & -0.06 & 1.06 & 4.91 & 0.22 & 0.24 & 3.70 & 0.07 & -2.37 & 5.29 & -0.45 \\
\hline Norway & 0.32 & 6.10 & 0.05 & -0.55 & 7.14 & -0.08 & 1.52 & 6.91 & 0.22 & 0.04 & 6.16 & 0.01 & 0.78 & 3.87 & 0.20 & -0.34 & 6.18 & -0.05 \\
\hline Spain & 0.86 & 7.17 & 0.12 & 4.24 & 13.26 & 0.32 & 0.22 & 4.51 & 0.05 & -0.50 & 5.61 & -0.09 & 0.89 & 3.68 & 0.24 & 0.02 & 5.48 & 0.00 \\
\hline Sweden & 0.16 & 5.57 & 0.03 & -0.62 & 6.46 & -0.10 & 0.57 & 5.01 & 0.11 & -0.04 & 6.64 & -0.01 & 1.23 & 4.50 & 0.27 & -0.48 & 5.19 & -0.09 \\
\hline Switzerland & -0.09 & 3.99 & -0.02 & -1.59 & 4.96 & -0.32 & 0.28 & 3.92 & 0.07 & 0.79 & 3.91 & 0.20 & 0.26 & 3.41 & 0.08 & -0.44 & 3.57 & -0.12 \\
\hline Malaysia & 0.60 & 10.46 & 0.06 & 0.61 & 10.36 & 0.06 & 1.10 & 4.44 & 0.25 & 2.18 & 7.76 & 0.28 & -1.65 & 6.72 & -0.25 & 0.74 & 17.86 & 0.04 \\
\hline Singapore & -0.02 & 6.66 & 0.00 & 0.23 & 9.48 & 0.02 & 0.55 & 4.18 & 0.33 & 0.55 & 4.55 & 0.12 & -1.50 & 3.53 & -0.43 & 0.12 & 9.55 & 0.01 \\
\hline South Africa & -0.09 & 6.28 & -0.01 & -1.64 & 7.06 & -0.23 & 1.48 & 5.54 & 0.27 & 0.11 & 5.31 & 0.02 & -0.17 & 4.53 & -0.04 & -0.50 & 8.31 & -0.06 \\
\hline
\end{tabular}


Table 4. (Continued). Value-Weighted Percentage Returns Model: FTSE Industry Effects (US dollar returns in percentage per month)

\begin{tabular}{|c|c|c|c|c|c|c|c|c|c|c|c|c|c|c|c|c|c|c|}
\hline & \multicolumn{3}{|c|}{$3: 1986$ to $8: 2000$} & \multicolumn{3}{|c|}{$3: 1986$ to $8: 1988$} & \multicolumn{3}{|c|}{$9: 1988$ to $8: 1991$} & \multicolumn{3}{|c|}{$9: 1991$ to $8: 1994$} & \multicolumn{3}{|c|}{$9: 1994$ to $8: 1997$} & \multicolumn{3}{|c|}{$9: 1997$ to $8: 2000$} \\
\hline & Mean & St Dev & Sharpe & Mean & St Dev & Sharpe & Mean & St Dey & Sharpe & Mean & St Dev & Sharpe & Mean & St Dev & Sharpe & Mean & St Dev & Sharpe \\
\hline South Korea & 1.14 & 12.18 & 0.09 & 3.30 & 10.12 & 0.00 & -0.31 & 7.53 & -0.04 & 0.73 & 9.00 & 0.08 & -1.14 & 6.51 & -0.18 & 3.48 & 21.24 & 0.16 \\
\hline Thailand & 0.92 & 11.23 & 0.08 & & & & 2.02 & 8.57 & 0.24 & 3.20 & 10.60 & 0.30 & -3.42 & 7.55 & -0.45 & 0.30 & 16.72 & 0.02 \\
\hline Philippines & 1.08 & 10.31 & 0.10 & & & & 2.68 & 11.27 & 0.24 & 2.95 & 9.64 & 0.31 & -0.99 & 8.59 & -0.12 & -0.92 & 12.34 & -0.07 \\
\hline Taiwan & 0.25 & 12.83 & 0.02 & & & & -0.52 & 16.70 & -0.03 & 1.21 & 13.80 & 0.09 & 0.55 & 8.11 & 0.07 & -2.56 & 9.74 & -0.26 \\
\hline Greece & 1.45 & 13.47 & 0.11 & & & & 5.93 & 22.28 & 0.27 & -1.75 & 8.35 & -0.21 & 1.23 & 5.73 & 0.21 & 0.94 & 12.00 & 0.08 \\
\hline Portugal & -0.14 & 6.33 & -0.02 & & & & 0.15 & 7.08 & 0.02 & -0.09 & 5.83 & -0.01 & 0.49 & 4.06 & 0.12 & -0.39 & 7.77 & -0.05 \\
\hline Argentina & 4.15 & 27.68 & 0.15 & & & & 13.57 & 52.24 & 0.26 & 2.22 & 10.43 & 0.21 & 0.45 & 7.15 & 0.06 & -1.36 & 8.48 & -0.16 \\
\hline Mexico & 1.37 & 9.32 & 0.15 & & & & 4.50 & 8.92 & 0.50 & 1.37 & 8.67 & 0.16 & -0.33 & 10.55 & -0.03 & 0.07 & 7.63 & 0.01 \\
\hline Turkey & 4.15 & 20.77 & 0.20 & & & & 5.62 & 25.19 & 0.22 & 5.78 & 23.50 & 0.25 & 4.66 & 14.93 & 0.31 & 3.47 & 19.41 & 0.18 \\
\hline Finland & 0.20 & 6.71 & 0.03 & & & & -1.75 & 6.97 & -0.25 & 1.44 & 7.86 & 0.18 & 0.40 & 5.34 & 0.08 & 0.72 & 6.59 & 0.11 \\
\hline Chile & 1.41 & 8.24 & 0.17 & & & & & & & 1.68 & 8.94 & 0.19 & 0.32 & 5.49 & 0.06 & -1.46 & 7.10 & -0.21 \\
\hline India & 1.53 & 14.23 & 0.11 & & & & & & & 4.73 & 21.30 & 0.22 & -1.38 & 7.91 & -0.17 & 0.59 & 10.26 & 0.06 \\
\hline Indonesia & -0.16 & 13.96 & -0.01 & & & & & & & 1.31 & 9.39 & 0.14 & -0.83 & 7.78 & -0.11 & 0.76 & 22.18 & 0.03 \\
\hline Peru & 2.08 & 15.60 & 0.13 & & & & & & & 7.79 & 20.59 & 0.38 & 1.70 & 8.48 & 0.20 & -1.06 & 7.49 & -0.14 \\
\hline Luxembourg & 0.17 & 5.13 & 0.03 & & & & & & & 0.79 & 4.45 & 0.18 & -0.44 & 3.63 & -0.12 & 0.24 & 6.77 & 0.04 \\
\hline Colombia & -0.72 & 9.06 & -0.08 & & & & & & & & & & -0.49 & 7.33 & -0.07 & -3.22 & 10.12 & -0.32 \\
\hline Poland & 2.88 & 17.65 & 0.16 & & & & & & & & & & 0.46 & 12.98 & 0.04 & -0.44 & 10.03 & -0.04 \\
\hline China & 2.73 & 22.75 & 0.12 & & & & & & & & & & 3.51 & 14.41 & 0.24 & 0.79 & 11.53 & 0.07 \\
\hline Average Abs. Country Effect & 0.82 & 9.06 & & 1.43 & 7.67 & & 1.66 & 8.78 & & 1.34 & 7.64 & & 0.94 & 5.60 & & 0.87 & 8.40 & \\
\hline Dispersion of Risk-Adjusted & & & & & & & & & & & & & & & & & & \\
\hline Country Premia & & & 0.08 & & & 0.21 & & & 0.16 & & & 0.16 & & & 0.22 & & & 0.14 \\
\hline
\end{tabular}


Table 5. Standard Deviations of country Index Returns, Pure Country Effects and Composite Industry Effects: Based on Value-Weighted Percentage Regressions without Size Effects

3.1986 to 8:2000

$3: 1986$ to $8: 1988$

9:1988 to $8: 1991$

9:1991 to $8: 1994$

9:1994 to 8:1997

9:1997 to 8:2000

Index Country Industry Index Country Industry Index Country Industry Index Country Industry Index Country Industry Index Country Industry

\begin{tabular}{|c|c|c|c|c|c|c|c|c|c|c|c|c|c|c|c|c|c|c|}
\hline United States & 4.58 & 3.40 & 0.61 & 6.24 & 4.35 & 0.81 & 4.26 & 4.53 & 0.41 & 2.99 & 3.13 & 0.24 & 3.38 & 1.88 & 0.32 & 5.43 & 2.01 & 0.91 \\
\hline United Kingdom & 5.09 & 3.41 & 0.81 & 7.08 & 4.74 & 0.76 & 6.32 & 3.95 & 0.50 & 4.71 & 3.41 & 0.23 & 2.66 & 2.23 & 0.37 & 4.11 & 2.21 & 1.45 \\
\hline France & 5.90 & 4.43 & 0.79 & 8.80 & 6.96 & 1.57 & 6.36 & 4.30 & 0.51 & 4.43 & 3.70 & 0.48 & 3.87 & 3.14 & 0.25 & 5.55 & 3.68 & 0.66 \\
\hline Germany & 5.77 & 4.91 & 0.81 & 7.12 & 6.73 & 1.15 & 7.37 & 5.70 & 0.56 & 3.75 & 4.04 & 0.37 & 3.97 & 3.41 & 0.35 & 6.05 & 4.05 & 1.21 \\
\hline Italy & 7.59 & 6.86 & 1.14 & 8.42 & 7.68 & 1.33 & 6.63 & 4.96 & 0.73 & 8.21 & 7.98 & 0,64 & 6.16 & 5.60 & 0.52 & 8.53 & 7.76 & 1.87 \\
\hline Japan & 7.68 & 4.76 & 0.41 & 8.01 & 4.38 & 0.61 & 8.89 & 4.29 & 0.31 & 7.74 & 5.28 & 0.19 & 5.50 & 3.69 & 0.18 & 7.39 & 5.47 & 0.59 \\
\hline Canada & 5.08 & 3.83 & 0.54 & 6.40 & 4.41 & 0.59 & 3.66 & 4.69 & 0.53 & 3.78 & 3.69 & 0.42 & 3.69 & 2.71 & 0.46 & 7.00 & 3.29 & 0.67 \\
\hline Australia & 6.70 & 5.90 & 1.14 & 11.41 & 10.52 & 1.13 & 5.60 & 6.02 & 1.13 & 5.28 & 4.52 & 0.67 & 3.72 & 3.02 & 0.69 & 6.01 & 3.65 & 1.65 \\
\hline Austria & 6.67 & 6.91 & 1.75 & 7.29 & 9.71 & 2.41 & 10.16 & 9.21 & 0.71 & 4.79 & 5.36 & 0.74 & 3.41 & 3.12 & 0.49 & 5.27 & 4.28 & 2.85 \\
\hline Belgium & 4.93 & 4.37 & 1.36 & 6.62 & 5.38 & 1.05 & 5.68 & 4.62 & 0.57 & 3.35 & 3.82 & 0.47 & 3.13 & 2.14 & 0.55 & 5.47 & 5.44 & 2.64 \\
\hline Denmark & 5.23 & 5.00 & 0.91 & 6.08 & 5.99 & 1.21 & 6.18 & 5.98 & 0.44 & 5.00 & 4.36 & 0.64 & 3.07 & 3.12 & 0.50 & 5.39 & 4.89 & 1.34 \\
\hline Hong Kong SAR & 9.50 & 8.36 & 1.15 & 10.62 & 10.55 & 1.62 & 7.49 & 5.91 & 0.87 & 8.87 & 8.74 & 0.72 & 6.49 & 5.30 & 0.63 & 13.21 & 10.58 & 1.58 \\
\hline Ireland & 6.41 & 5.29 & 1.04 & 8.86 & 8.09 & 1.13 & 7.18 & 4.72 & 0.46 & 5.79 & 4.77 & 0.79 & 2.52 & 2.29 & 0.62 & 6.72 & 5.80 & 1.62 \\
\hline Netherlands & 4.44 & 3.28 & 1.21 & 5.51 & 3.58 & 1.23 & 4.26 & 3.27 & 1.09 & 3.56 & 2.87 & 0.68 & 3.50 & 1.93 & 0.50 & 5.35 & 4.15 & 1.90 \\
\hline New Zealand & 8.37 & 7.86 & 1.30 & 14.08 & 14.56 & 2.23 & 7.76 & 7.44 & 0.46 & 6.37 & 4.91 & 0.51 & 3.79 & 3.70 & 0.60 & 7.95 & 5.29 & 1.75 \\
\hline Norway & 7.39 & 6.10 & 1.42 & 9.12 & 7.14 & 1.32 & 7.33 & 6.91 & 1.40 & 7.72 & 6.16 & 0.87 & 3.99 & 3.87 & 0.78 & 8.41 & 6.18 & 2.15 \\
\hline Spain & 9.22 & 7.17 & 1.77 & 16.79 & 13.26 & 3.46 & 6.54 & 4.51 & 0.76 & 6.85 & 5.61 & 0.74 & 4.30 & 3.68 & 0.69 & 7.39 & 5.48 & 1.91 \\
\hline Sweden & 7.29 & 5.57 & 1.26 & 6.97 & 6.46 & 1.53 & 7.92 & 5.01 & 0.97 & 8.35 & 6.64 & 0.67 & 5.15 & 4.50 & 0.72 & 7.88 & 5.19 & 1.90 \\
\hline Switzerland & 5.12 & 3.99 & 1.42 & 5.88 & 4.96 & 1.14 & 6.14 & 3.92 & 0.54 & 4.36 & 3.91 & 0.91 & 3.78 & 3.41 & 0.81 & 5.46 & 3.57 & 2.55 \\
\hline Malaysia & 11.58 & 10.46 & 1.11 & 11.60 & 10.36 & 0.95 & 6.41 & 4.44 & 0.36 & 7.67 & 7.76 & 0.36 & 7.61 & 6.72 & 0.43 & 19.55 & 17.86 & 2.12 \\
\hline Singapore & 7.97 & 6.66 & 0.99 & 50.28 & 9.48 & 1.52 & 6.31 & 4.18 & 0.79 & 4.89 & 4.55 & 0.58 & 4.22 & 3.53 & 0.46 & 11.78 & 9.55 & 1.33 \\
\hline South Africa & 7.51 & 6.28 & 1.80 & 8.75 & 7.06 & 2.33 & 6.08 & 5.54 & 1.76 & 5.14 & 5.31 & 0.88 & 4.74 & 4.53 & 0.69 & 11.33 & 8.31 & 2.54 \\
\hline South Korea & 13.04 & 12.18 & 0.94 & 9.85 & 10.12 & 1.34 & 8.94 & 7.53 & 0.64 & 8.96 & 9.00 & 0.44 & 6.80 & 6.51 & 0.43 & 22.90 & 21.24 & 1.37 \\
\hline Thailand & 12.53 & 11.23 & 1.19 & & & & 9.39 & 8.57 & 1.09 & 9.94 & 10.60 & 0.61 & 8.28 & 7.55 & 0.43 & 19.67 & 16.72 & 1.71 \\
\hline Philippines & 11.58 & 10.31 & 1.30 & & & & 12.85 & 11.27 & 0.91 & 9.53 & 9.64 & 0.65 & 8.99 & 8.59 & 0.55 & 15.21 & 12.34 & 2.27 \\
\hline Taiwan & 13.39 & 12.83 & 1.42 & & & & 17.16 & 16.70 & 0.96 & 14.31 & 13.80 & 0.45 & 8.74 & 8.11 & 0.77 & 10.86 & 9.74 & 2.39 \\
\hline Greece & 13.17 & 13.47 & 1.10 & & & & 21.40 & 22.28 & 1.21 & 7.98 & 8.35 & 0.74 & 5.60 & 5.73 & 0.63 & 12.44 & 12.00 & 1.59 \\
\hline Portugal & 6.62 & 6.33 & 1.26 & & & & 7.35 & 7.08 & 0.92 & 6.05 & 5.83 & 0.91 & 4.06 & 4.06 & 0.70 & 8.38 & 7.77 & 2.03 \\
\hline Argentina & 27.23 & 27.68 & 1.41 & & & & 50.76 & 52.24 & 1.31 & 11.59 & 10.43 & 0.67 & 8.16 & 7.15 & 0.49 & 10.18 & 8.48 & 2.29 \\
\hline Mexico & 10.10 & 9.32 & 1.01 & & & & 9.14 & 8.92 & 1.04 & 8.73 & 8.67 & 0.58 & 11.39 & 10.55 & 0.45 & 10.09 & 7.63 & 1.46 \\
\hline Turkey & 20.47 & 20.77 & 1.50 & & & & 24.02 & 25.19 & 1.12 & 23.13 & 23.50 & 0.67 & 14.97 & 14.93 & 0.48 & 20.22 & 19.41 & 2.51 \\
\hline Finland & 8.50 & 6.71 & 2.29 & & & & 6.95 & 6.97 & 0.78 & 9.14 & 7.86 & 0.84 & 6.38 & 5.34 & 1.17 & 10.60 & 6.59 & 4.19 \\
\hline Chile & 7.90 & 8.24 & 1.51 & & & & & & & 8.35 & 8.94 & 0.76 & 5.82 & 5.49 & 0.82 & 8.26 & 7.10 & 2.52 \\
\hline India & 13.82 & 14.23 & 0.88 & & & & & & & 20.56 & 21.30 & 0.71 & 8.21 & 7.91 & 0.51 & 10.93 & 10.26 & 1.12 \\
\hline Indonesia & 15.00 & 13.96 & 1.44 & & & & & & & 9.25 & 9.39 & 0.86 & 9.05 & 7.78 & 0.54 & 23.95 & 22.18 & 2.38 \\
\hline Peru & 15.19 & 15.60 & 2.38 & & & & & & & 19.80 & 20.59 & 1.40 & 8.23 & 8.48 & 0.64 & 7.95 & 7.49 & 3.82 \\
\hline Luxembourg & 4.57 & 5.13 & 1.44 & & & & & & & 4.27 & 4.45 & 0.65 & 2.76 & 3.63 & 0.64 & 6.04 & 6.77 & 2.22 \\
\hline Colombia & 8.67 & 9.06 & 1.79 & & & & & & & & & & 6.48 & 7.33 & 0.69 & 10.23 & 10.12 & 2.86 \\
\hline Poland & 18.90 & 17.65 & 1.14 & & & & & & & & & & 13.15 & 12.98 & 0.61 & 12.61 & 10.03 & 1.74 \\
\hline China & 22.57 & 22.75 & 1.40 & & & & & & & & & & 14.25 & 14.41 & 0.55 & 10.68 & 11.53 & 2.04 \\
\hline Average Total & 9.83 & 9.06 & 1.25 & 8.77 & 7.67 & 1.41 & 9.77 & 8.78 & 0.81 & 7.98 & 7.64 & 0.64 & 6.10 & 5.60 & 0.57 & 10.06 & 8.40 & 1.94 \\
\hline Average Industrial & 6.34 & 5.30 & 1.18 & 8.37 & 7.16 & 1.37 & 6.63 & 5.40 & 0.69 & 5.55 & 4.87 & 0.60 & 3.94 & 3.36 & 0.57 & 6.68 & 4.93 & 1.81 \\
\hline
\end{tabular}


Table 6. "Pure" Country Effects and Composite Industry Effects in Percentage Country Portfolio Return Standard Deviation (Based on Value-Weighted Percentage Regressions without Size Effects (Table 6))

\begin{tabular}{|c|c|c|c|c|c|c|c|c|c|c|c|c|}
\hline & \multicolumn{2}{|c|}{$3: 1986$ to $8: 2000$} & \multicolumn{2}{|c|}{$3: 1986$ to $8: 1988$} & \multicolumn{2}{|c|}{$9: 1988$ to $8: 1991$} & \multicolumn{2}{|c|}{$9: 1991$ to $8: 1994$} & \multicolumn{2}{|c|}{$9: 1994$ to $8: 1997$} & \multicolumn{2}{|c|}{$9: 1997$ to $8: 2000$} \\
\hline & Country & Industry & Country & Industry & Country & Industry & Country & Industry & Country & Industry & Country & Industry \\
\hline United States & 74.32 & 13.26 & 69.73 & 13.00 & 106.28 & .9 .58 & 104.79 & 8.00 & 55.45 & 9.57 & 36.96 & 16.75 \\
\hline United Kingdom & 66.99 & 15.86 & 66.94 & 10.68 & 62.38 & 7.94 & 72.46 & 4.94 & 83.99 & 14.07 & 53.65 & 35.25 \\
\hline France & 75.13 & 13.46 & 79.04 & 17.83 & 67.65 & 8.09 & 83.45 & 10.94 & 81.21 & 6.59 & 66.35 & 11.94 \\
\hline Germany & 85.19 & 14.08 & 94.45 & 16.08 & 77.35 & 7.54 & 107.75 & 9.82 & 85.98 & 8.89 & 66.87 & 19.99 \\
\hline Italy & 90.29 & 15.07 & 91.14 & 15.82 & 74.83 & 11.07 & 97.16 & 7.81 & 90.88 & 8.39 & 90.90 & 21.97 \\
\hline Japan & 61.95 & 5.40 & 54.67 & 7.63 & 48.23 & 3.47 & 68.31 & 2.42 & 67.13 & 3.32 & 73.97 & 8.04 \\
\hline Canada & 75.43 & 10.58 & 69.01 & 9.17 & 128.38 & 14.47 & 97.69 & 11.07 & 73.37 & 12.50 & 46.96 & 9.60 \\
\hline Australia & 88.10 & 16.97 & 92.18 & 9.86 & 107.56 & 20.26 & 85.64 & 12.76 & 81.32 & 18.66 & 60.67 & 27.40 \\
\hline Austria & 103.64 & 26.26 & 133.21 & 32.99 & 90.62 & 7.03 & 111.80 & 15.36 & 91.52 & 14.30 & 81.24 & 54.08 \\
\hline Belgium & 88.74 & 27.55 & 81.24 & 15.83 & 81.33 & 10.05 & 114.22 & 14.04 & 68.34 & 17.55 & 99.46 & 48.22 \\
\hline Denmark & 95.64 & 17.35 & 98.52 & 19.89 & 96.72 & 7.18 & 87.21 & 12.82 & 101.79 & 16.35 & 90.71 & 24.84 \\
\hline Hong Kong SAR & 88.00 & 12.15 & 99.26 & 15.22 & 78.88 & 11.55 & 98.53 & 8.17 & 81.71 & 9.77 & 80.06 & 11.94 \\
\hline Ireland & 82.64 & 16.18 & 91.32 & 12.79 & 65.67 & 6.47 & 82.43 & 13.64 & 90.89 & 24.46 & 86.26 & 24.16 \\
\hline Netherlands & 73.92 & 27.23 & 64.97 & 22.37 & 76.64 & 25.56 & 80.66 & 19.11 & 55.18 & 14.17 & 77.51 & 35.46 \\
\hline New Zealand & 93.88 & 15.55 & 103.43 & 15.87 & 95.80 & 5.88 & 77.11 & 7.97 & 97.66 & 15.89 & 66.54 & 22.08 \\
\hline Norway & 82.56 & 19.20 & 78.31 & 14.45 & 94.34 & 19.16 & 79.82 & 11.28 & 96.98 & 19.52 & 73.46 & 25.59 \\
\hline Spain & 77.75 & 19.23 & 78.97 & 20.58 & 68.95 & 11.59 & 81.92 & 10.83 & 85.42 & 16.13 & 74.18 & 25.81 \\
\hline Sweden & 76.38 & 17.21 & 92.69 & 21.93 & 63.29 & 12.21 & 79.55 & 8.08 & 87.36 & 13.97 & 65.89 & 24.17 \\
\hline Switzerland & 77.79 & 27.73 & 84.47 & 19.40 & 63.82 & 8.80 & 89.48 & 20.77 & 90.40 & 21.50 & 65.44 & 46.68 \\
\hline Malaysia & 90.36 & 9.59 & 89.29 & 8.15 & 69.22 & 5.57 & 101.12 & 4.69 & 88.27 & 5.59 & 91.38 & 10.83 \\
\hline Singapore & 83.55 & 12.47 & 92.19 & 14.75 & 66.21 & 12.45 & 92.99 & 11.93 & 83.74 & 11.01 & 81.12 & 11.30 \\
\hline South Africa & 83.55 & 23.94 & 80.76 & 26.66 & 91.17 & 28.95 & 103.36 & 17.17 & 95.58 & 14.59 & 73.39 & 22.43 \\
\hline South Korea & 93.39 & 7.24 & 102.72 & 13.59 & 84.26 & 7.15 & 100.44 & 4.88 & 95.75 & 6.36 & 92.74 & 5.97 \\
\hline Thailand & 89.62 & 9.50 & & & 91.21 & 11.55 & 106.57 & 6.17 & 91.19 & 5.16 & 84.99 & 8.71 \\
\hline Philippines & 89.07 & 11.22 & & & 87.74 & 7.07 & 101.14 & 6.79 & 95.59 & 6.08 & 81.13 & 14.90 \\
\hline Taiwan & 95.79 & 10.60 & & & 97.31 & 5.60 & 96.39 & 3.11 & 92,74 & 8.83 & 89.68 & 22.00 \\
\hline Greece & 102.27 & 8.38 & & & 104.11 & 5.65 & 104.55 & 9.24 & 102.38 & 11.33 & 96.47 & 12.77 \\
\hline Portugal & 95.69 & 19.06 & & & 96.32 & 12.45 & 96.41 & 15.07 & 100.01 & 17.32 & 92.76 & 24.27 \\
\hline Argentina & 101.67 & 5.18 & & & 102.93 & 2.58 & 89.92 & 5.75 & 87.60 & 5.97 & 83.30 & 22.49 \\
\hline Mexico & 92.26 & 10.02 & & & 97.59 & 11.43 & 99.32 & 6.69 & 92.65 & 3.95 & 75.69 & 14.50 \\
\hline Turkey & 101.48 & 7.31 & & & 104.88 & 4.65 & 101.60 & 2.90 & 99.74 & 3.19 & 95.99 & 12.42 \\
\hline Finland & 78.89 & 26.96 & & & 100.32 & 11.20 & 85.98 & 9.15 & 83.68 & 18.40 & 62.15 & 39.56 \\
\hline Chile & 104.36 & 19.12 & & & & & 107.06 & 9.13 & 94.23 & 14.16 & 85.96 & 30.56 \\
\hline India & 102.96 & 6.36 & & & & & 103.62 & 3.45 & 96.26 & 6.19 & 93.88 & 10.28 \\
\hline Indonesia & 93.10 & 9.58 & & & & & 101.53 & 9.29 & 85.96 & 5.98 & 92.61 & 9.92 \\
\hline Peru & 102.75 & 15.70 & & & & & 103.98 & 7.08 & 103.06 & 7.84 & 94.28 & 48.06 \\
\hline Luxembourg & 112.35 & 31.51 & & & & & 104.28 & 15.33 & 131.60 & 23.22 & 112.13 & 36.72 \\
\hline Colombia & 104.44 & 20.67 & & & & & & & 113.14 & 10.57 & 98.97 & 27.97 \\
\hline Poland & 93.37 & 6.04 & & & & & & & 98.73 & 4.63 & 79.51 & 13.79 \\
\hline China & 100.78 & 6.20 & & & & & & & 101.12 & 3.84 & 107.94 & 19.12 \\
\hline Average Total & 89.25 & 15.17 & 86.46 & 16.28 & 85.69 & 10.44 & 94.60 & 9.67 & 89.99 & 11.49 & 80.58 & 22.81 \\
\hline Average Industrial & 83.68 & 18.84 & 84.68 & 16.45 & 83.32 & 11.00 & 89.91 & 11.49 & 85.72 & 14.99 & 73.53 & 27.74 \\
\hline
\end{tabular}


Table 7. Value-Weighted Dollar Returns Model: FTSE Industry Effects “ Size Effects (US Dollar returns in percentage per month)

\begin{tabular}{|c|c|c|c|c|c|c|c|c|c|c|c|c|c|c|c|c|c|c|}
\hline & \multicolumn{3}{|c|}{$3: 1986$ to $8: 2000$} & \multicolumn{3}{|c|}{$3: 1986$ to $8: 1988$} & \multicolumn{3}{|c|}{$9: 1988$ to $8: 1991$} & \multicolumn{3}{|c|}{$9: 1991$ to $8: 1994$} & \multicolumn{3}{|c|}{$9: 1994$ to $8: 1997$} & \multicolumn{3}{|c|}{$9: 1997$ to $8: 2000$} \\
\hline & Mean & St Dev & Sharpe & Mean & St Dev & Sharpe & Mean & St Dev & Sharpe & Mean & St Dev & Sharpe & Mean & St Dev & Sharpe & Mean & St Dev & Sharpe \\
\hline Resources & -0.37 & 3.70 & -0.10 & 0.49 & 3.20 & 0.15 & -0.04 & 3.15 & -0.01 & -0.23 & 2.19 & -0.11 & -0.24 & 2.03 & -0.12 & -1.69 & 6.14 & -0.28 \\
\hline Basic Industries & -0.44 & 2.53 & -0.17 & 0.39 & 2.22 & 0.17 & -0.09 & 2.16 & -0.04 & 0.00 & 1.48 & 0.00 & -0.65 & 1.03 & -0.63 & -1.72 & 4.11 & -0.42 \\
\hline General Industries & -0.01 & 1.87 & -0.01 & -0.26 & 3.13 & -0.08 & 0.21 & 1.57 & 0.13 & 0.08 & 1.38 & 0.06 & 0.05 & 0.73 & 0.07 & -0.17 & 2.02 & -0.08 \\
\hline $\begin{array}{l}\text { Cyclical Consumer } \\
\text { Goods }\end{array}$ & -0.18 & 2.96 & -0.06 & 0.06 & 4.34 & 0.01 & -0.32 & 1.96 & -0.16 & 0.22 & 2.22 & 0.10 & 0.17 & 1.60 & 0.11 & -1.01 & 3.91 & -0.26 \\
\hline $\begin{array}{l}\text { Non-Cyclical } \\
\text { Consumer Goods }\end{array}$ & -0.14 & 2.37 & -0.06 & -0.05 & 2.32 & -0.02 & 0.53 & 1.47 & 0.36 & -0.42 & 1.83 & -0.23 & 0.12 & 1.39 & 0.08 & -0.87 & 3.84 & -0.23 \\
\hline Cyclical Services & -0.08 & 1.44 & -0.06 & -0.17 & 2.17 & -0.08 & 0.26 & 1.02 & 0.25 & 0.04 & 1.00 & 0.04 & -0.29 & 1.06 & -0.27 & -0.27 & 1.73 & -0.16 \\
\hline $\begin{array}{l}\text { Non-Cyclical } \\
\text { Services }\end{array}$ & -0.30 & 3.52 & -0.08 & -0.50 & 6.04 & -0.08 & -0.95 & 3.04 & -0.31 & 0.07 & 1.84 & 0.04 & -0.49 & 1.65 & -0.30 & 0.35 & 3.81 & 0.09 \\
\hline Utilities & -0.62 & 4.24 & -0.15 & -0.54 & 6.96 & -0.08 & -0.08 & 3.09 & -0.03 & -0.32 & 1,86 & -0.17 & -0.84 & 1.91 & -0.44 & -1.31 & 5.58 & -0.24 \\
\hline $\begin{array}{l}\text { Information } \\
\text { Technology }\end{array}$ & 0.95 & 4.60 & 0.21 & -0.40 & 5.03 & -0.08 & -0.42 & 3.19 & -0.13 & 0.88 & 2.10 & 0.42 & 1.47 & 3.80 & 0.39 & 3.00 & 6.82 & 0.44 \\
\hline Financials & -0.16 & 2.82 & -0.06 & 0.04 & 4.08 & 0.01 & -0.06 & 1.91 & -0.03 & 0.05 & 1.60 & 0.03 & 0.05 & 1.1 .5 & 0.05 & -0.87 & 4.15 & -0.21 \\
\hline Ist Quintile & -0.37 & 2.37 & -0.15 & -0.07 & 1.74 & -0.04 & -0.46 & 2.01 & -0.23 & -0.29 & 1.90 & -0.15 & -0.25 & 1.68 & $-0.1,5$ & -0.71 & 3.83 & -0.19 \\
\hline 2nd Quintile & -0.27 & 1.93 & -0.14 & -0.36 & 2.13 & -0.17 & -0.21 & 1.64 & -0.13 & -0.08 & 1.49 & -0.05 & -0.37 & 1.25 & -0.30 & -0.37 & 2.86 & -0.13 \\
\hline 3rd Quintile & -0.20 & 1.88 & -0.11 & -0.66 & 2.45 & -0.27 & -0.07 & 1.94 & -0.03 & 0.08 & 1.19 & 0.06 & -0.23 & 1.10 & -0.21 & -0.22 & 2.41 & -0.09 \\
\hline 4th Quintile & -0.15 & 1.27 & -0.11 & -0.49 & 1.91 & -0.25 & 0.03 & 1.17 & 0.03 & 0.13 & 0.76 & 0.17 & -0.25 & 0.83 & -0.31 & -0.20 & 1.46 & -0.14 \\
\hline 5th Quintile & 0.05 & 0.42 & 0.12 & 0.17 & 0.64 & 0.26 & 0.00 & 0.45 & 0.01 & -0.03 & 0.29 & -0.09 & 0.08 & 0.27 & 0.30 & 0.05 & 0.38 & 0.14 \\
\hline Global Factor & 2.04 & 4.51 & 0.45 & 2.94 & 5.23 & 0.56 & 1.28 & 5.44 & 0.24 & 1.67 & 3.42 & 0.49 & 1.56 & 3.04 & 0.51 & 2.92 & 5.00 & 0.58 \\
\hline United States & -0.03 & 3.40 & -0.01 & -1.64 & 4.43 & -0.37 & 0.65 & 4.52 & 0.14 & -0.38 & 3.09 & -0.12 & 0.88 & 1.86 & 0.47 & 0.06 & 1.93 & 0.03 \\
\hline United Kingdom & -0.02 & 3.39 & -0.01 & -0.88 & 4.66 & -0.19 & 0.80 & 3.95 & 0.20 & -0.26 & 3.42 & -0.08 & 0.41 & 2.24 & 0.19 & -0.32 & 2.21 & -0.14 \\
\hline France & 0.03 & 4.47 & 0.01 & -0.68 & 7.07 & -0.10 & 0.68 & 4.34 & 0.16 & -0.18 & 3.70 & -0.05 & -0.29 & 3.15 & -0.09 & 0.48 & 3.69 & 0.13 \\
\hline Germany & -0.48 & 4.91 & -0.10 & -2.46 & 6.71 & -0.37 & 0.67 & 5.71 & 0.12 & -0.42 & 4.05 & -0.10 & -0.07 & 3.41 & -0.02 & -0.46 & 4.05 & -0.11 \\
\hline Italy & -0.35 & 6.86 & -0.05 & -1.75 & 7.81 & -0.22 & -0.16 & 4.93 & -0.03 & -0.71 & 7.95 & -0.09 & -0.35 & 5.56 & -0.06 & 0.98 & 7.77 & 0.13 \\
\hline Japan & -0.32 & 4.74 & -0.07 & 1.75 & 4.31 & 0.41 & -0.94 & 4.26 & -0.22 & -0.14 & 5.30 & -0.03 & -1.68 & 3.69 & -0.46 & -0.23 & 5.44 & -0.04 \\
\hline Canada & -0.10 & 3.77 & -0.03 & -1.09 & 4.17 & -0.26 & 0.08 & 4.64 & 0.02 & -0.83 & 3.77 & -0.22 & 0.74 & 2.67 & 0.28 & 0.42 & 3.26 & 0.13 \\
\hline Australia & -0.01 & 5.76 & 0.00 & 1.10 & 10.09 & 0.11 & -0.06 & 5.93 & -0.01 & -0.16 & 4.58 & -0.03 & 0.00 & 2.99 & 0.00 & -0.72 & 3.59 & -0.20 \\
\hline Austria & -0.25 & 6.57 & -0.04 & -2.06 & 9.15 & -0.22 & 2.99 & 8.54 & 0.35 & -0.88 & 5.37 & -0.16 & -0.49 & 2.98 & -0.16 & -1.13 & 4.28 & -0.26 \\
\hline Belgium & -0.13 & 4.23 & -0.03 & -0.06 & 4.69 & -0.01 & -0.03 & 4.44 & -0.01 & -0.16 & 3.87 & -0.04 & 0.22 & 2.21 & 0.10 & -0.64 & 5.48 & -0.12 \\
\hline Denmark & -0.02 & 4.96 & -0.01 & -1.29 & 5.77 & -0.22 & 1.49 & 6.21 & 0.24 & -0.75 & 4.15 & -0.18 & 0.56 & 3.10 & 0.18 & -0.34 & 4.90 & -0.07 \\
\hline Hong Kong & 0.94 & 8.25 & 0.11 & 0.27 & 10.10 & 0.03 & 1.04 & 5.84 & 0.18 & 1.98 & 8.73 & 0.23 & 0.76 & 5.30 & 0.14 & 0.56 & 10.59 & 0.05 \\
\hline Ireland & 0.43 & 5.05 & 0.09 & 0.78 & 7.43 & 0.11 & 0.26 & 4.41 & 0.06 & 0.35 & 4.83 & 0.07 & 0.91 & 2.11 & 0.43 & -0.07 & 5.69 & -0.01 \\
\hline
\end{tabular}


Table 7 (Continued). Value-Weighted Dollar Returns Model: FTSE Industry Effects-Size Effects

(US Dollar returns in percentage per month)

\begin{tabular}{|c|c|c|c|c|c|c|c|c|c|c|c|c|c|c|c|c|c|c|}
\hline & \multicolumn{3}{|c|}{$3: 1986$ to $8: 2000$} & \multicolumn{3}{|c|}{$3: 1986$ to $8: 1988$} & \multicolumn{3}{|c|}{$9: 1988$ to $8: 1991$} & \multicolumn{3}{|c|}{$9: 1991$ to $8: 1994$} & \multicolumn{3}{|c|}{$9: 1994$ to $8: 1997$} & \multicolumn{3}{|c|}{$9: 1997$ to $8: 2000$} \\
\hline & Mean & St Dev & Sharpe & Mean & St Dev & Sharpe & Mean & St Dev & Sharpe & Mean & St Dev & Sharpe & Mean & St Dev & Sharpe & Mean & St Dev & Sharpe \\
\hline Netherlands & -0.06 & 3.26 & -0.02 & -1.45 & 3.48 & -0.42 & 0.15 & 3.26 & 0.05 & 0.24 & 2.87 & 0.09 & 0.76 & 1.92 & 0.40 & -0.23 & 4.17 & -0.05 \\
\hline New Zealand & -0.61 & 7.90 & -0.08 & -2.21 & 14.51 & -0.15 & -0.39 & 7.21 & -0.05 & 1.02 & 5.08 & 0.20 & 0.36 & 3.76 & 0.09 & -2.11 & 5.82 & -0.36 \\
\hline Norway & 0.48 & 5.90 & 0.08 & -0.04 & 6.44 & -0.01 & 1.57 & 6,82 & 0.23 & 0.02 & 6.19 & 0.00 & 0.94 & 3.66 & 0.26 & -0.18 & 6.10 & -0.03 \\
\hline Spain & 0.90 & 7.06 & 0.13 & 4.34 & 12.95 & 0.34 & 0.23 & 4.42 & 0.05 & -0.50 & 5.59 & -0.09 & 0.94 & 3.66 & 0.26 & 0.07 & 5.49 & 0.01 \\
\hline Sweden & 0.22 & 5.57 & 0.04 & -0.33 & 6.42 & -0.05 & 0.61 & 5.07 & 0.12 & -0.08 & 6.63 & -0.01 & 1.29 & 4.50 & 0.29 & -0.48 & 5.20 & -0.09 \\
\hline Switzerland & -0.03 & 3.92 & -0.01 & -1.35 & 4.69 & -0.29 & 0.35 & 3.98 & 0.09 & 0.82 & 3.88 & 0.21 & 0.26 & 3.41 & 0.08 & -0.44 & 3.57 & -0.12 \\
\hline Malaysia & 0.74 & 10.24 & 0.07 & 1.06 & 10.06 & 0.11 & 1.17 & 3.78 & 0.31 & 2.16 & 7.85 & 0.28 & -1.55 & 6.74 & -0.23 & 0.93 & 17.48 & 0.05 \\
\hline Singapore & 0.09 & 6.52 & 0.01 & 0.56 & 9.12 & 0.06 & 0.60 & 3.74 & 0.16 & 0.53 & 4.61 & 0.12 & -1.42 & 3.44 & -0.41 & 0.23 & 9.55 & 0.02 \\
\hline South Africa & -0.04 & 6.23 & -0.01 & -1.53 & 7.18 & -0.21 & 1.49 & 5.55 & 0.27 & 0.08 & 5.32 & 0.01 & -0.09 & 4.55 & $-0,02$ & -0.39 & 8.05 & -0.05 \\
\hline South Korea & 1.28 & 12.11 & 0.11 & 3.70 & 10.03 & 0.37 & -0.27 & 7.57 & -0.04 & 0.72 & 9.06 & 0.08 & -1.01 & 6.45 & -0.16 & 3.65 & 21.02 & 0.17 \\
\hline Thailand & 0.96 & 10.78 & 0.09 & & & & 2.13 & 7.91 & 0.27 & 3.18 & 10.76 & 0.30 & -3.32 & 7.77 & -0.43 & 0.69 & 16.66 & 0.04 \\
\hline Philippines & 1.06 & 9.73 & 0.11 & & & & 2.78 & 11.01 & 0.25 & 2.85 & 9.90 & 0.29 & -0.85 & 8.48 & -0.10 & -0.57 & 12.40 & -0.05 \\
\hline Taiwan & 0.23 & 12.13 & 0.02 & & & & -0.50 & 16.75 & -0.03 & 1.19 & 13.83 & 0.09 & 0.57 & 8.11 & 0.07 & -2.51 & 9.80 & -0.26 \\
\hline Greece & 1.36 & 12.35 & 0.11 & & & & 6.17 & 21.71 & 0.28 & -1.77 & 8.39 & -0.21 & 1.39 & 5.57 & 0.25 & 1.09 & 11.91 & 0.09 \\
\hline Portugal & -0.03 & 5.75 & 0.00 & & & & 0.30 & 6.62 & 0.05 & -0.06 & 5.75 & -0.01 & 0.71 & 4.10 & 0.17 & -0.28 & 7.64 & -0.04 \\
\hline Argentina & 3.74 & 25.71 & 0.15 & & & & 13.88 & 51.92 & 0.27 & 2.28 & 10.55 & 0.22 & 0.65 & 7.17 & 0.09 & -1.13 & 8.18 & -0.14 \\
\hline Mexico & 1.26 & 8.63 & 0.15 & & & & 4.58 & 8.64 & 0.53 & 1.35 & 8.72 & 0.16 & -0.16 & 10.54 & -0.02 & 0.21 & 7.59 & 0.03 \\
\hline Turkey & 3.68 & 19.34 & 0.19 & - & & & 5.68 & 24.75 & 0.23 & 5.82 & 23.56 & 0.25 & 4.87 & 14.97 & 0.33 & 3.63 & 19.44 & 0.19 \\
\hline Finland & 0.24 & 6.11 & 0.04 & & & & -1.63 & 6.75 & -0.24 & 1.46 & 7.77 & 0.19 & 0.51 & 5.31 & 0.10 & 0.78 & 6.57 & 0.12 \\
\hline Chile & 1.13 & 7.11 & 0.16 & & & & & & & 1.62 & 8.90 & 0.18 & 0.44 & 5.43 & 0.08 & -1.26 & 6.70 & -0.19 \\
\hline India & 1.18 & 12.06 & 0.10 & & & & & & & 4.71 & 21.35 & 0.22 & -1.24 & 7.79 & -0.16 & 0.72 & 9.79 & 0,07 \\
\hline Indonesia & -0.03 & 11.81 & 0.00 & & & & & & & 1.25 & 9.53 & 0.13 & -0.74 & 7.87 & -0.09 & 1.04 & 22.21 & 0.05 \\
\hline Peru & 1.56 & 12.59 & 0.12 & & & & & & & 7.82 & 20.59 & 0.38 & 2.03 & 8.18 & 0.25 & -0.61 & 7.11 & -0.09 \\
\hline Luxembourg & 0.18 & 3.67 & 0.05 & & & & & & & 0.62 & 4.07 & 0.15 & -0.19 & 3.11 & -0.06 & 0.45 & 6.32 & 0.07 \\
\hline Colombia & -0.27 & 6.69 & -0.04 & & & & & & & & & & -0.25 & 6.94 & -0.04 & -2.67 & 9.61 & -0.28 \\
\hline Poland & 1.85 & 13.39 & 0.14 & & & & & & & & & & 0.75 & 12.88 & 0.06 & -0.08 & 9.96 & -0.01 \\
\hline China & 1.50 & 16.58 & 0.09 & & & & & & & & & & 3.68 & 14.30 & 0.26 & 0.92 & 11.01 & 0.08 \\
\hline
\end{tabular}


Figure 1: The Global Factor and Industry Effects on Stock Returns (3-year rolling standard deviations)
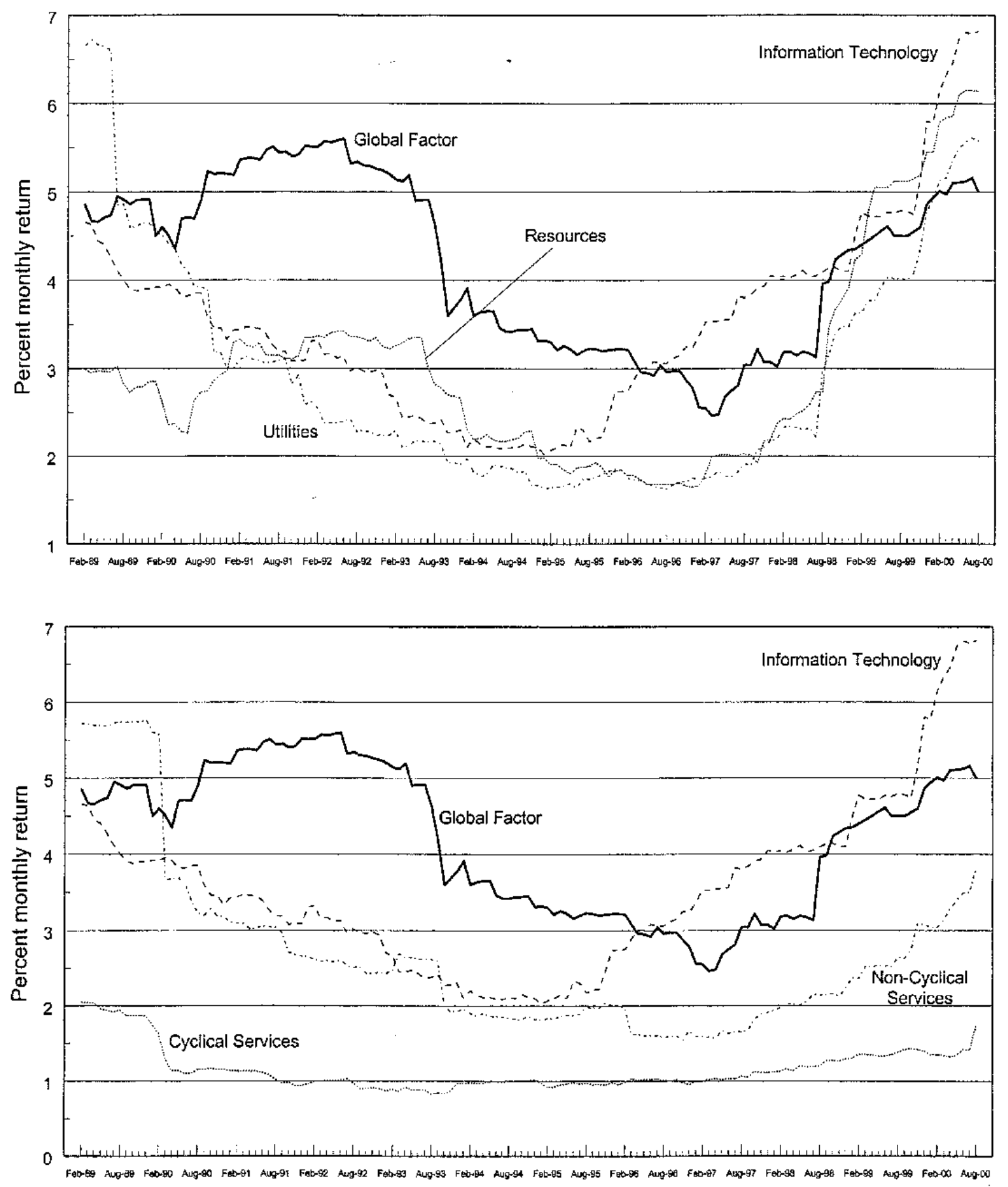
Figure 2: The Global Factor and Country Effects on Stock Returns (3-year rolling standard deviations)
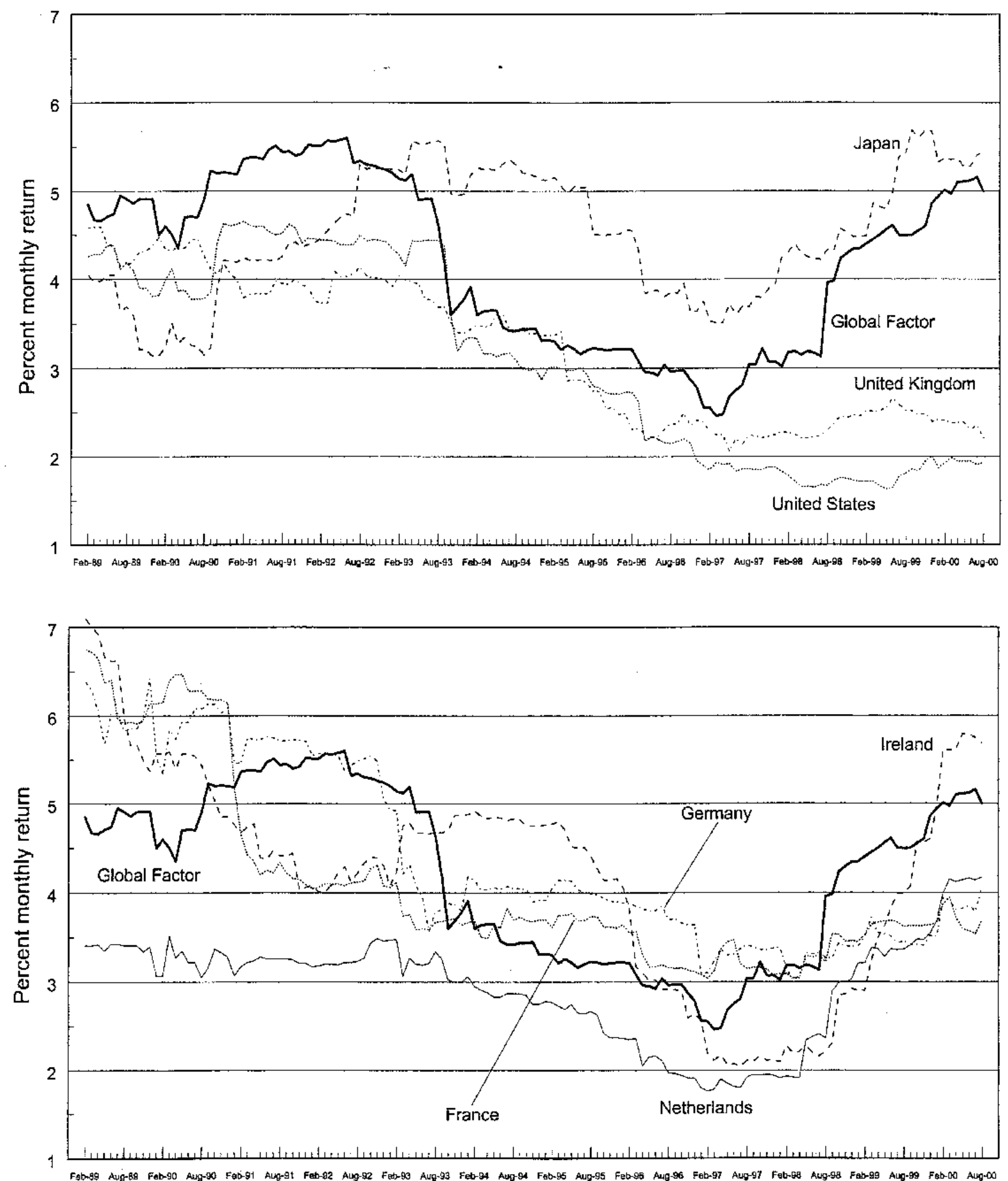
Figure 3: The Global Factor and Asian/Latin American Country Effects on Stock Returns

(3-year rolling standard deviations)
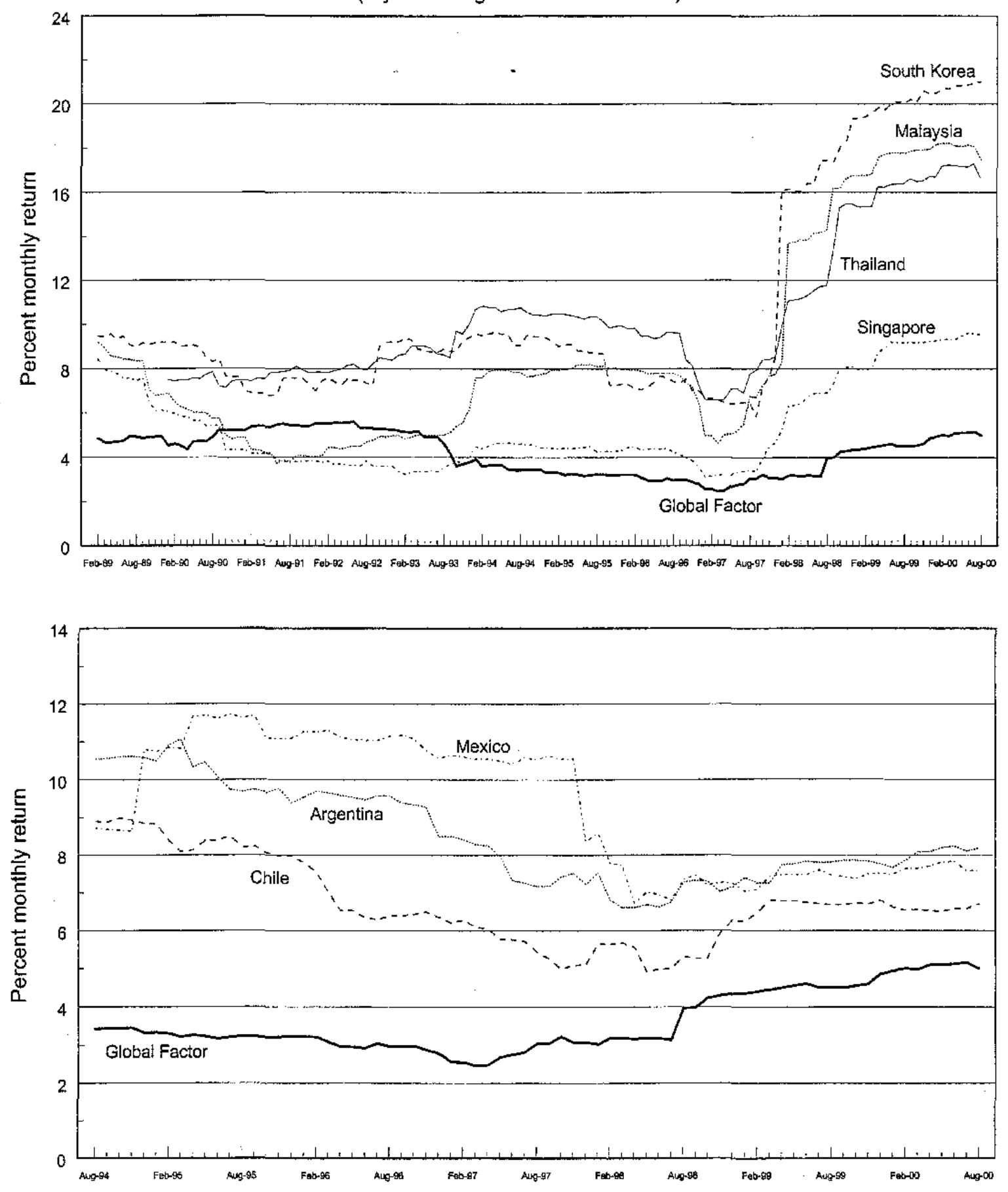
Figure 4: Cummulative Industry Effects on Global Stock Returns

(Cummulative Monthly Returns (Feb $1986=100$ )

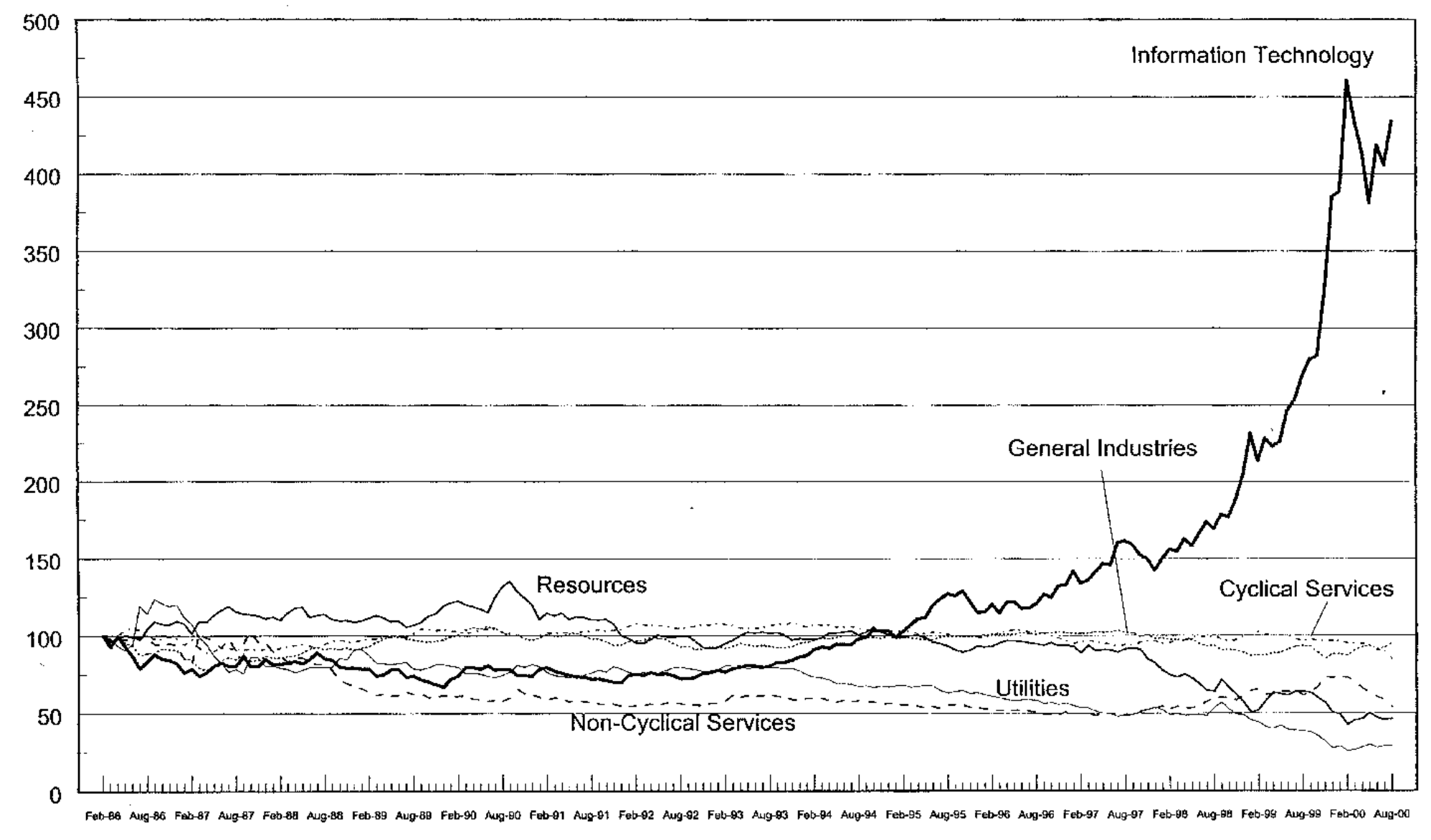


Figure 5: The Global Factor and Firm Size Effects on Stock Returns

(3-year rolling standard deviations)

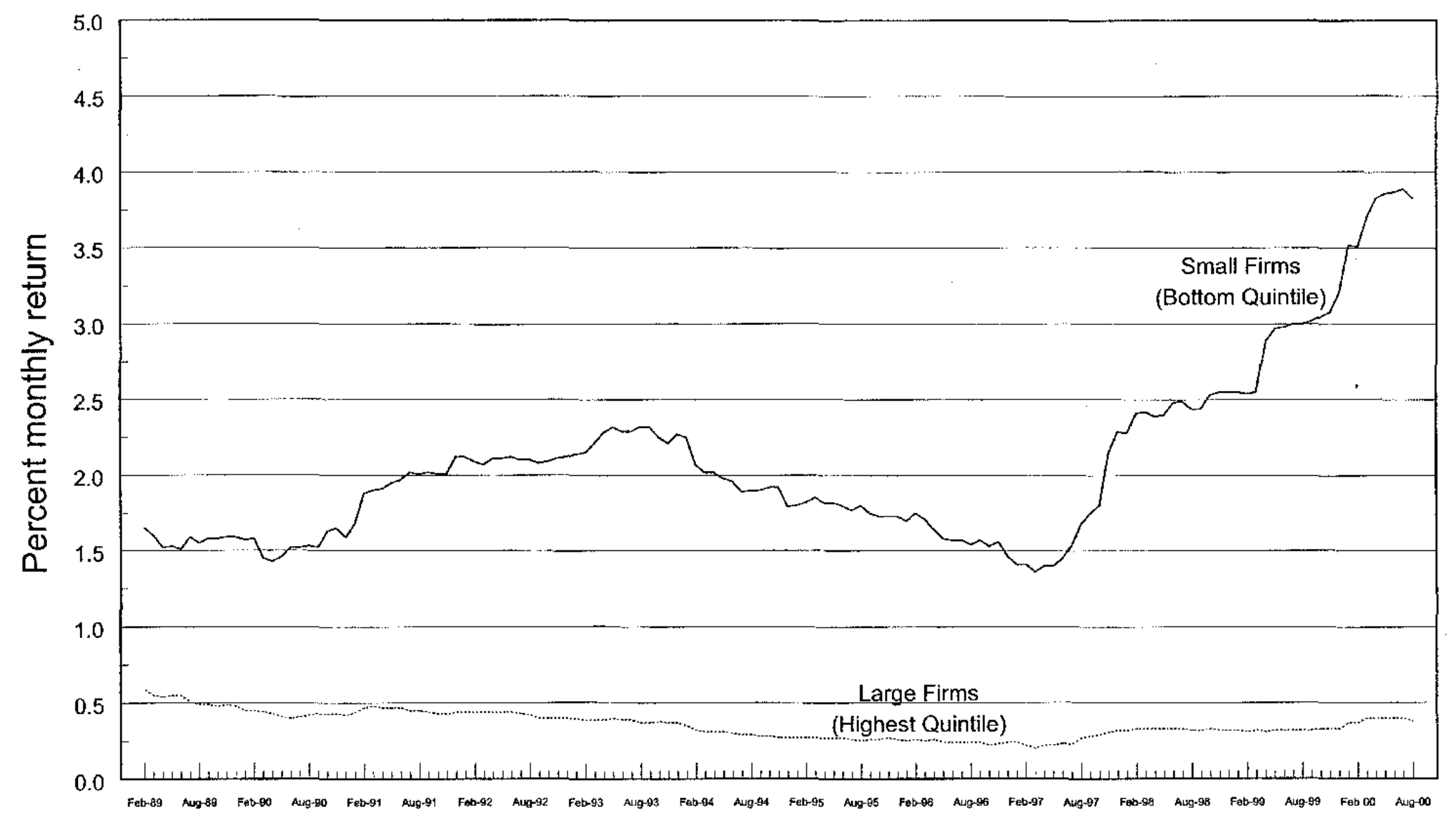


Figure 6: Standard Deviation of Residuals of Value Weighted Model with Size Effects

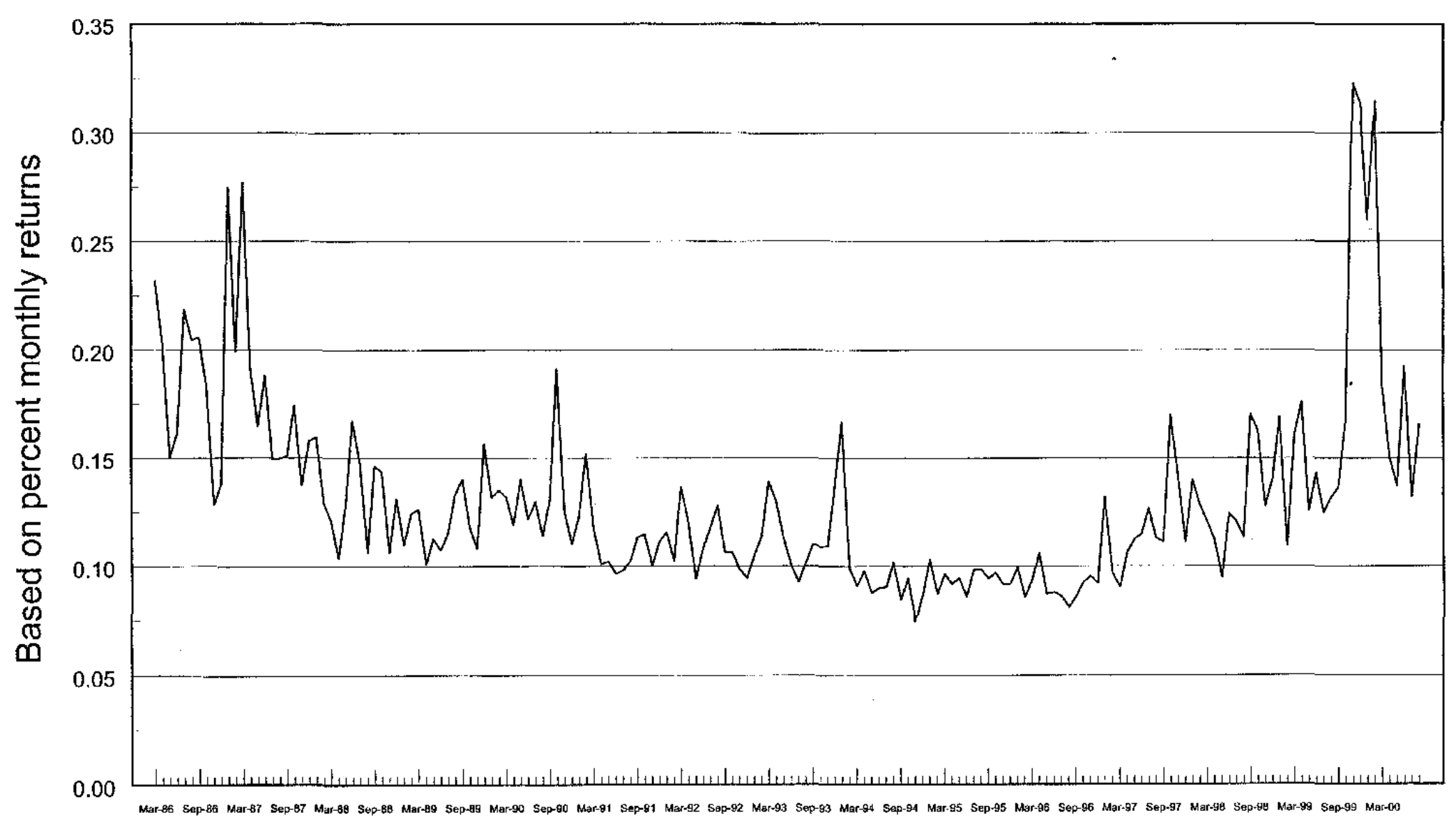




\section{The Data}

Each firm in the sample is assigned to one of 10 broad industry categories, which are based on the FTSE sector indices. These sector indices break down in the following way:

1) Resources

- Mining

- Oil \& Gas

2) Basic Industries

- Chemicals

- Construction \& Building Materials

- Forestry \& Paper

- Steel \& Other Metals

3) General Industries

- Aerospace \& Defense

- Diversified Industrials

- Electronic \& Electrical Equipment

- Engineering \& Machinery

4) Cyclical Consumer Goods

- Automobiles

- Household Goods \& Textiles

5) Non-Cyclical Consumer Goods

- Beverages

- Food Producers \& Processors

- Health

- Packaging

- Personal Care \& Household Products

- Pharmaceuticals

- Tobacco

6) Cyclical Services

- Distributors

- General Retailers

- Leisure, Entertainment \& Hotels

- Media \& Photography 
- Restaurants, Pubs \& Breweries

- Support Services

- Transport

7) Non-Cyclical Services

- Food \& Drug Retailers

- Telecommunication Services

8) Utilities

- Electricity

- Gas Distribution

- Water

9) Financials

- Banks

- Insurance

- Life Assurance

- Investment Companies

- Real Estate

- Specialty \& Other Finance

10) Information Technology

- Information Technology Hardware

- Software \& Computer Services

Datastream/Primark provides an additional "new economy" versus "old economy" breakdown:

a) Technology, Media \& Telecommunication (TMT)

- Information Technology Hardware

- Software \& Computer Services

- Media \& Photography

- Telecommunication Services

b) Non-TMT

All other companies 